\title{
PGRMC1 phosphorylation affects cell shape, motility, glycolysis, mitochondrial form and function, and tumor growth
}

Bashar M. Thejer ${ }^{1,2 \dagger}$, Partho P. Adhikary ${ }^{1,3+}$, Amandeep Kaur ${ }^{4,5}$, Sarah L. Teakel ${ }^{1}$, Ashleigh Van Oosterum ${ }^{6}$, Ishith Seth ${ }^{1}$, Marina Pajic ${ }^{7,8}$, Katherine M. Hannan ${ }^{9,10}$, Megan Pavy ${ }^{10}$, Perlita Poh ${ }^{10}$, Jalal A. Jazayeri ${ }^{1}$, Thiri Zaw ${ }^{11}$, Dana Pascovici ${ }^{11}$, Marina Ludescher ${ }^{12}$, Michael Pawlak ${ }^{13}$, Juan C. Cassano ${ }^{14}$, Lynne Turnbull15,16, Mitra Jazayeri ${ }^{17}$, Alexander C. James ${ }^{18,19,20}$, Craig P. Coorey ${ }^{18,21}$, Tara L. Roberts ${ }^{18,19,20,21}$, Simon J. Kinder ${ }^{22}$, Ross D. Hannan 9,10,23,24,25, Ellis Patrick ${ }^{26}$, Mark P. Molloy ${ }^{11,27}$, Elizabeth J. New ${ }^{4}$, Tanja N. Fehm² ${ }^{12}$, Hans Neubauer ${ }^{12}$, Ewa M. Goldys ${ }^{28,29}$, Leslie A. Weston ${ }^{30,31}$ and Michael A. Cahill ${ }^{1,10^{*}}$

\begin{abstract}
Background: Progesterone Receptor Membrane Component 1 (PGRMC1) is expressed in many cancer cells, where it is associated with detrimental patient outcomes. It contains phosphorylated tyrosines which evolutionarily preceded deuterostome gastrulation and tissue differentiation mechanisms.

Results: We demonstrate that manipulating PGRMC1 phosphorylation status in MIA PaCa-2 (MP) cells imposes broad pleiotropic effects. Relative to parental cells over-expressing hemagglutinin-tagged wild-type (WT) PGRMC1HA, cells expressing a PGRMC1-HA-S57A/S181A double mutant (DM) exhibited reduced levels of proteins involved in energy metabolism and mitochondrial function, and altered glucose metabolism suggesting modulation of the Warburg effect. This was associated with increased PI3KJAKT activity, altered cell shape, actin cytoskeleton, motility, and mitochondrial properties. An S57A/Y180F/S181A triple mutant (TM) indicated the involvement of Y180 in PI3K AKT activation. Mutation of Y180F strongly attenuated subcutaneous xenograft tumor growth in NOD-SCID gamma mice. Elsewhere we demonstrate altered metabolism, mutation incidence, and epigenetic status in these cells.
\end{abstract}

Conclusions: Altogether, these results indicate that mutational manipulation of PGRMC1 phosphorylation status exerts broad pleiotropic effects relevant to cancer and other cell biology.

Keywords: Mitochondria, Migration, Invasion, Metabolism, Cytochrome P450, Mesenchymal amoeboid transition, Proteomics, Tumor biology

\footnotetext{
* Correspondence: mcahill@csu.edu.au

${ }^{\dagger}$ Bashar M. Thejer and Partho P. Adhikary are Co-first author.

'School of Biomedical Sciences, Charles Sturt University, Wagga Wagga, NSW 2650, Australia

${ }^{10}$ ACRF Department of Cancer Biology and Therapeutics, The John Curtin

School of Medical Research, The Australian National University, ACT, Canberra 2601, Australia

Full list of author information is available at the end of the article
}

(c) The Author(s). 2020 Open Access This article is licensed under a Creative Commons Attribution 4.0 International License, which permits use, sharing, adaptation, distribution and reproduction in any medium or format, as long as you give appropriate credit to the original author(s) and the source, provide a link to the Creative Commons licence, and indicate if changes were made. The images or other third party material in this article are included in the article's Creative Commons licence, unless indicated otherwise in a credit line to the material. If material is not included in the article's Creative Commons licence and your intended use is not permitted by statutory regulation or exceeds the permitted use, you will need to obtain permission directly from the copyright holder. To view a copy of this licence, visit http://creativecommons.org/licenses/by/4.0/ The Creative Commons Public Domain Dedication waiver (http://creativecommons.org/publicdomain/zero/1.0/) applies to the data made available in this article, unless otherwise stated in a credit line to the data. 


\section{Summary statement}

PGRMC1 phosphorylation site mutations cause pleiotropic plasticity-related changes including altered mitochondrial form and function, PI3K/AKT activity, migration, and glucose consumption. Efficient mouse xenograft tumor formation required Y180.

\section{Background}

Progesterone (P4) Receptor Membrane Component 1 (PGRMC1) is a cytochrome $b_{5}$-related heme-binding protein with multiple functions including interaction with cytochrome P450 enzymes. Briefly, (the reader is referred to previous reviews) non-comprehensive PGRMC1 functions include membrane trafficking, P4 responsiveness and steroidogenesis, fertility, lipid transport, neural axon migration, synaptic function, and anti-apoptosis. Its subcellular localization can be cytoplasmic, nuclear/nucleolar, mitochondrial, endoplasmic reticulum, cytoplasmic vesicles, or extracellular [1-3]. It is involved in cell cycle processes at the G1 checkpoint and during mitosis [4-9], and elevated PGRMC1 expression has been associated with poor prognosis in multiple types of cancer [2, 10-15].

Predicted binding site motifs for Src homology 2 (SH2) and Src homology 3 (SH3) proteins in PGRMC1 can potentially be negatively regulated by phosphorylation at adjacent casein kinase 2 (CK2) consensus sites $[2,16,17]$. However, while CK2 knockdown leads to reduced phosphorylation of the corresponding C-terminal CK2 site of PGRMC2, PGRMC1 phosphorylation at S181 was unaffected by CK2 knockout in C2C12 mouse myoblast cells [18]. These and Y180 can all be phosphorylated in vivo, and constitute a potential regulated signaling module [19].

We hypothesized that PGRMC1 is a signal hub protein with wide ranging effects on cell biology [2, 19-21]. The highly conserved motif at Y180/S181 phosphorylation arose early in animal evolution concurrently with the embryological organizer of gastrulation (e.g. SpemannMangold organizer), and prior to the evolution of deuterostomes $[20,22]$. Since all of the descendants of the organism that first acquired S181 exhibit bilateral body symmetry, this mutation predated the rules governing cell growth and division leading to bilateral body plan and more types of tissues. The mechanisms that generate and maintain cell- and tissue-type differentiation states are very often perturbed in cancer [23]. Therefore, PGRMC1 tyrosine phosphorylation could potentially strongly influence mammalian cell function and differentiation status.

This present study was prompted by our discovery of differential PGRMC1 phosphorylation status between estrogen receptor-positive and -negative breast cancers [24]. PGRMC1 was induced in the hypoxic zone of ductal carcinoma in situ breast lesions at precisely the time and place that cells require a switch to glycolytic metabolism known as the Warburg effect, leading us to predict a Warburg-mediating role for PGRMC1. Furthermore, a PGRMC1 S57A/S181A double CK2 site mutant (DM, Fig. 1a) enabled the survival of peroxide treatment [24]. Sabbir [25] recently reported that PGRMC1 induced a P4-dependent metabolic change resembling the Warburg effect in HEK293 cells, which was associated with changes in PGRMC1 stability, posttranslational modifications, and subcellular locations. PGRMC1 regulation of glucose metabolism is supported by its implicated mediation of the placental P4dependent shift from aerobic towards anaerobic glucose metabolism in gestational diabetes [26], association with the insulin receptor and glucose transporters [27], and probable involvement (based upon AG-205 sensitivity) in P4-mediated increase in neuronal glycolysis [28].

We previously observed that MIA PaCa-2 pancreatic cancer (MP) cells [29-32] exhibited marked morphological and metabolic changes when the DM protein was expressed [33]. MP cells exist in culture as a mixed adherent population of elongated "fibroblast-shaped" morphology, a minority population of rounded morphology with bleb-like protrusions, and some multicellular clumps, as well as some rounded suspension cells. They have undergone epithelial-mesenchymal transition [34], and can further undergo mesenchymal-amoeboid transition (MAT), which requires Rho Kinase- (ROCK)dependent morphological change from "elongated" mesenchymal cells to rounded amoeboid cells [35].

Here, we mutagenically examined the effects of altered PGRMC1 phosphorylation status on MP cells to gain insights into PGRMC1-dependent signaling in vitro, revealing an important role for Y180. Our objectives were to initially characterize the effects of mutations at the two DM putative negative regulatory phosphorylation sites, S57 and S181, on cell biology, as well as mutating Y180 which forms the center of a putative SH2 target motif to test the hypothesis that the DM effect required Y180. Importantly this investigation was extended to an in vivo system, specifically a subcutaneous mouse xenograft tumorigenesis model, in order to address the requirement of Y180 for tumor development in a complex environment. In a companion publication [36], we describe differences in metabolism, genomic mutation rates, and epigenetic genomic CpG methylation levels associated with the PGRMC1 phosphorylation mutants described in this present study.

\section{Results}

PGRMC1 phosphorylation status alters cellular morphology

We stably transfected MP cells with the hemagglutinin (HA) epitope-tagged PGRMC1-HA plasmids including 
A

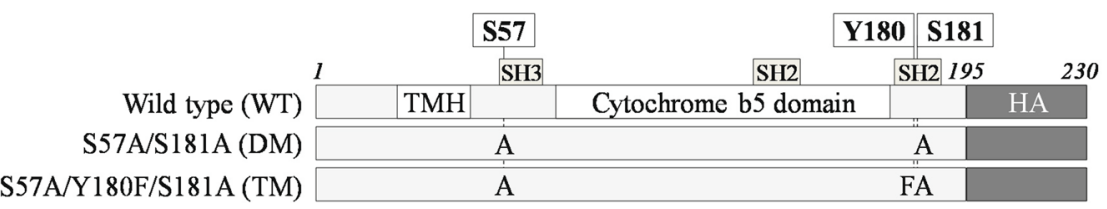

B

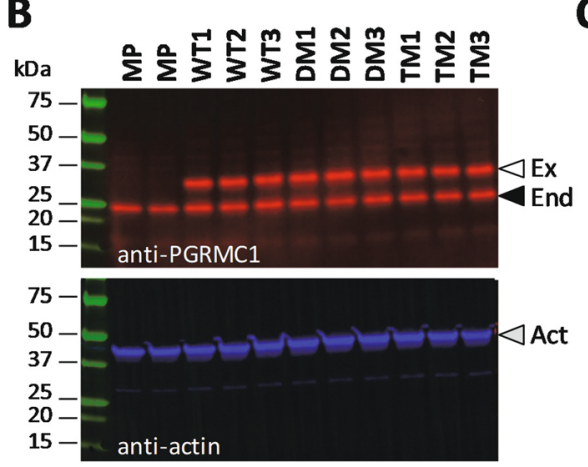

C
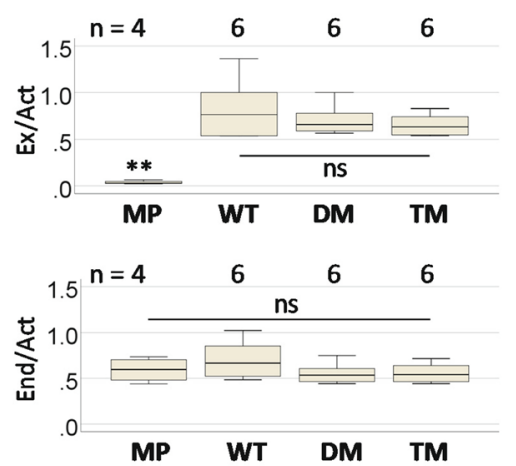

D

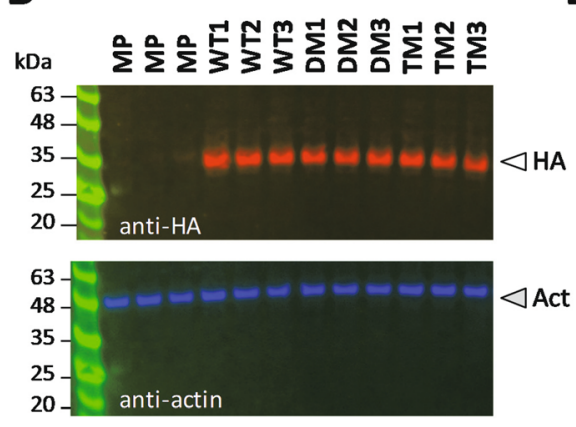

F

DM

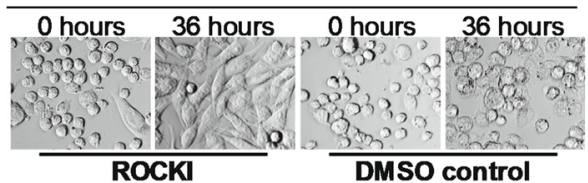

E

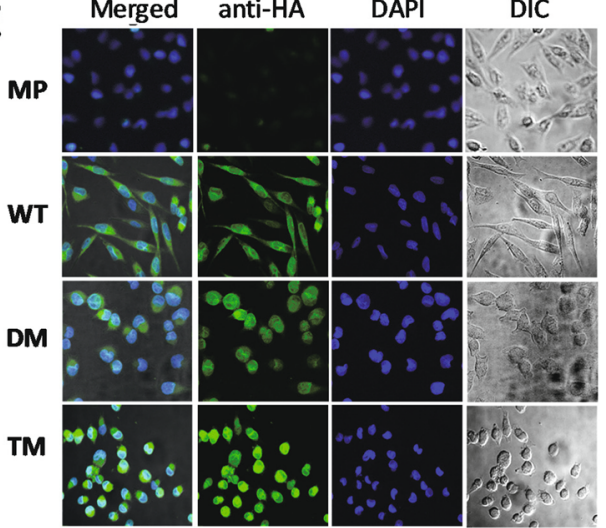

TM

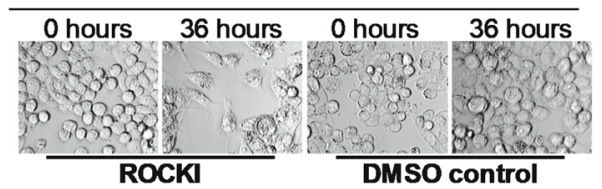

Fig. 1 MIA PaCa-2 pancreatic cancer cells morphology is affected by PGRMC1 phosphorylation status. a PGRMC1-HA proteins constructed for this figure. TMH: Trans-membrane helix. HA: the C-terminal $3 x$ hemaglutinin tag. b Detection of exogenous PGRMC1 expression levels by western blot (upper panel). Equal loading is controlled by quantifying beta actin (lower panel). The results show three totally independent stably transfected cell lines per plasmid from (A). Open arrow: Exogenous PGRMC1-HA (Ex.). Shaded arrow: endogenous PGRMC1 (End.). Filled arrow: beta actin. The molecular weight ladder is Bio-Rad 1610377 Dual Xtra Standards. c Box plots quantification of replicate gels of (B) with signals normalized to beta actin from the same respective lanes. $n=4$ lanes for MP and $n=6$ for WT, DM and TM (replicates of respective lines 1-3 per condition). There were no significant differences (ns) except for the exogenous band in MP (ANOVA, post-hoc Dunnet's T3). $\mathbf{d}$ Western blot quantification of HA-tagged exogenous PGRMC1, following B but detecting PGRMC1 with anti-HA antibody. The molecular weight ladder is Abcam ab116028 Prestained Protein Ladder. e PGRMC1 mutant protein expression alters MIA PaCa-2 cell morphology. PGRMC1-HA-expressing stable cells (respective lines 1 from B) or MP cells were stained with a FITC-tagged anti-HA antibody (Anti-HA) and imaged by confocal microscopy. DNA was stained with DAPI. Cells were also imaged in differential interference contrast (DIC) microscopy mode. The respective left panels show merged images of all 3 channels. $\mathbf{f}$ The rounded phenotype of double and triple mutant (E) was reversed to elongated phenotype after $125 \mu \mathrm{M}$ ROCKI addition, but not by addition of DMSO vehicle control

the wild-type (WT) sequence [37], the S57A/S181A DM [24], or a novel S57A/Y180F/S181A triple mutant (TM), which removed the phosphate acceptor of Y180 [16, 19, 20] (Fig. 1a). Three independent stable cell lines from each group expressed both $32 \mathrm{kDa} 3 x \mathrm{xH}$-tagged exogenous and a $24 \mathrm{kDa}$ endogenous PGRMC1 species, whereas only the $24 \mathrm{kDa}$ species was present in MP cells (Fig. 1bd). Both species were present at approximately equimolar ratios, and an anti-HA antibody detected only the 32 $\mathrm{kDa}$ species (Fig. 1d). We reason that any consistent differences between biological triplicates should be due to PGRMC1-HA mutations, rather than clonal artifacts. 
Subsequent experiments were performed using respective cell line triplicates 1-3 per PGRMC1-HA condition. However, note that MP cells have not undergone hygromycin selection for stably-integrated plasmids, therefore cells in the WT/MP comparison differ by two variables (selection and PGRMC1-HA). We focus our analysis onto comparisons between WT, DM and TM cells.

Like MP cells, freshly seeded WT cells exhibited predominantly elongated cell morphology with some rounded cells. DM and TM cells exhibited primarily rounded morphology (Fig. 1e), which was reminiscent of the reported MAT of MP cells [35]. After $72 \mathrm{~h}$ of culture the proportion of round cells in DM and TM cultures was reduced, but still elevated relative to WT or MP (not shown). Transient transfections with the DM and TM plasmids (but not WT) led to similar increased levels of cell rounding across the entire populations of cells by $24 \mathrm{~h}$ after transfection (data not shown), indicating that the phosphorylation status of exogenous PGRMC1-HA affects cell morphology.

\section{PGRMC1-dependent altered morphology requires rho kinase}

The ROCK pathway is required for amoeboid phenotype and migration and its inhibition reverses MAT in MP cells $[35,38]$. ROCK inhibitor (ROCKI) reversed the rounded phenotype to elongated for DM and TM (Fig. 1f), supporting the hypothesis that morphological transition involves altered actin organization. It remains unclear whether the process is truly MAT.

\section{PGRMC1 phosphorylation affects cell motility and invasion}

To further investigate cell plasticity imposed by PGRMC1-HA phosphorylation mutants, we examined cell motility via a scratch assay [39]. MP cells exhibited the lowest migration, while DM cell migration was substantially greater than other cell lines (Fig. 2a-b, File S1). DM cells migrated predominantly as rounded cells, using extended filopodia and small pseudopodia, however, a minority of flattened cells exhibited more pronounced pseudopodia. Video imaging demonstrated that these cell shapes could rapidly interconvert (File S1C). Conversely, DM cells exhibited the lowest ability to invade through a Geltrex pseudo-basal membrane (Fig. 2c-d).

\section{PGRMC1 phosphorylation imposes broad changes}

A total of 1330 proteins were reliably identified by proteomics in at least one sample with at least 2 peptides using a combination of information dependent acquisition (IDA) and data independent SWATH-MS (Sequential Window Acquisition of all Theoretical Mass Spectrometry) acquisition. Results are provided as File
S2. Approximately $50 \%$ of variation was explained by two principal components (PCs) in PC analysis, which corresponded approximately to "ribosomes and translation" (PC1, separated MP\&DM from WT\&TM) and "mRNA splicing and processing" (PC2, separated MP\&WT from DM\&TM) (Fig. S1A, File S3). Of the identified proteins, 243 differed by 1.5 fold or more between one or more comparisons with $p<0.05$ (t-test), and 235 of these withstood PC multiple sample correction. The heat map clustering of those 243 proteins (Fig. 3, File S6) revealed a suite of proteins which strongly discriminated between the different PGRMC1HA-induced conditions. Biological replicates clustered tightly in clades of the same cell type, with large distances between clades. We conclude that these differences are primarily specific PGRMC1-HA mutantdependent effects.

Results from those six comparisons of protein abundance between the four sample types (1) MP v. WT, 2) MP v. DM, 3) MP v. TM, 4) WT v. DM, 5) WT v. TM, and 6) DM v. TM] provide lists of significantly differentially abundant proteins in each pair-wise comparison (File S2). WebGestalt enrichment analyses were performed to identify pathways or features either significantly more or less abundant (respectively the "red" and "blue" lists of proteins for each comparison from columns B of File S4) between each of the respective six comparisons at the Benjamini-Hochberg adjusted $p$ value $(\operatorname{adj} P)<0.001$ level in at least one pairwise comparison. WebGestalt mapped features (File S5) are plotted against the heat map in File S6 (for primary WebGestalt data see File S5 and File S6). The results are schematically mapped against the 243 protein heat map in Fig. 3, using all pathways that were detected by WebGestalt in any of the inter-sample comparisons at the $\operatorname{adj} \mathrm{P}<0.001$ level, and including all proteins detected in any of those pathways across all 12 comparisons at the $\operatorname{adj} \mathrm{P}<0.1$ level for respective red and blue protein lists from File S4.

WT PGRMC1-HA protein induced the elevated abundance of many proteins involved in energy metabolism, including proteasomal components involved in protein degradation, and pathways for amino acid, carbohydrate, and fatty acid catabolism (Fig. 3). These proteins were annotated as both cytoplasmic and mitochondrial. Peroxisomal and lysosomal proteins were also upregulated in WT cells. A suite of proteins putatively involved in the recognition of mRNA by ribosomes, tRNA aminoacylation, ribosomal protein translation, and chaperonemediated protein folding, was generally less abundant in WT and TM than MP and DM cells (Fig. 3, File S6). Many of the changes in fatty acid and glucose metabolism enzymes resemble the effects of the insulin/glucagon system of metabolic regulation. 

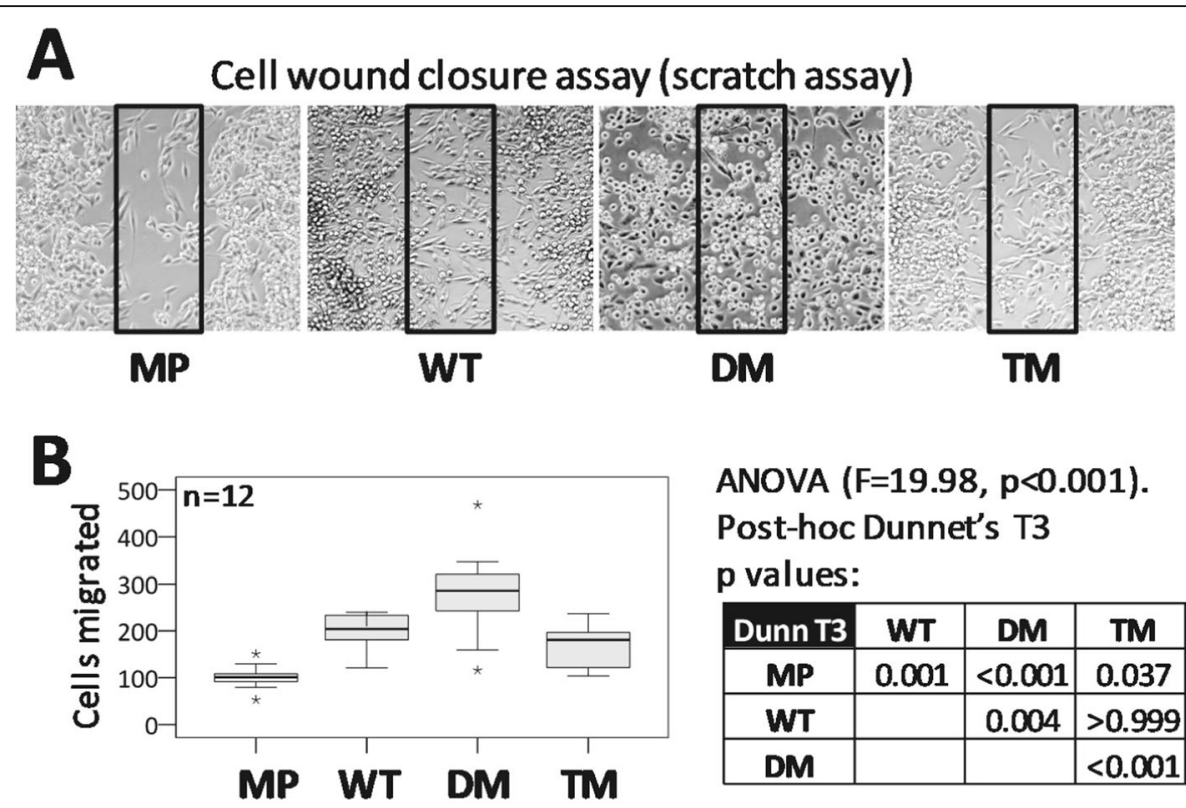

ANOVA (F=19.98, p<0.001).

Post-hoc Dunnet's T3

p values:

\begin{tabular}{|c|c|c|c|}
\hline Dunn T3 & WT & DM & TM \\
\hline MP & 0.001 & $<0.001$ & 0.037 \\
\hline WT & & 0.004 & $>0.999$ \\
\hline DM & & & $<0.001$ \\
\hline
\end{tabular}
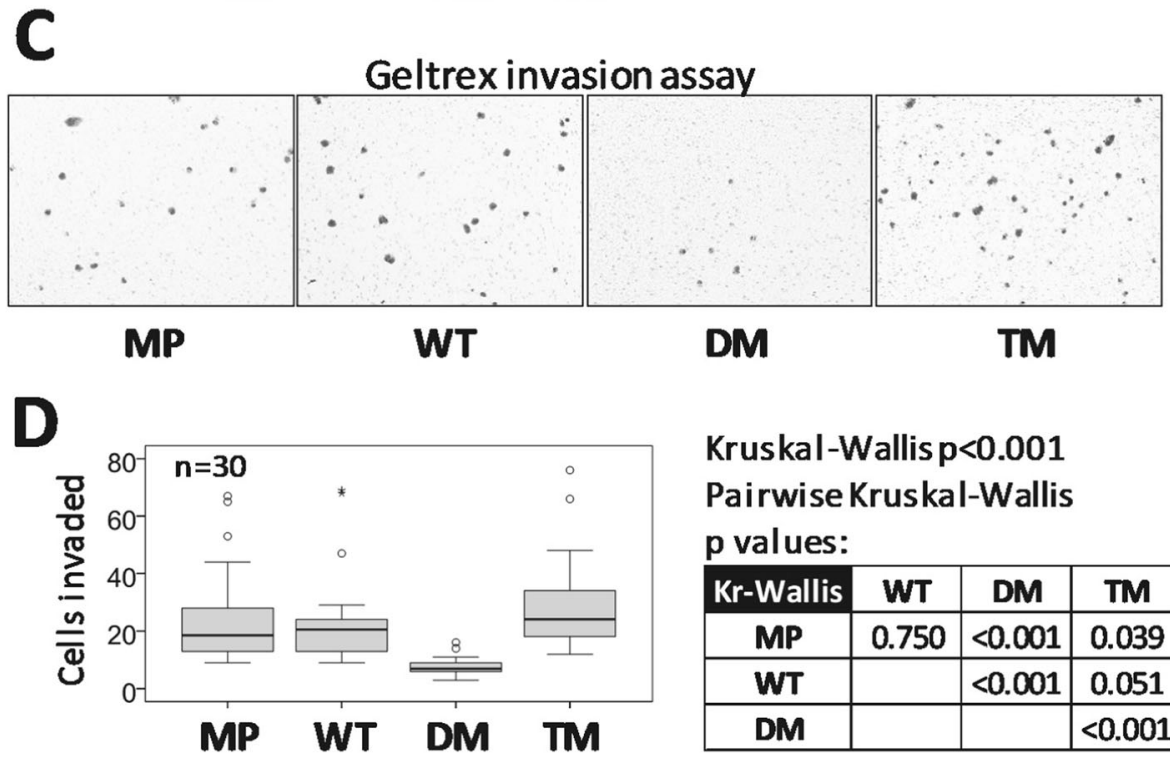

Kruskal-Wallis $p<0.001$
Pairwise Kruskal-Wallis
p values:
\begin{tabular}{|c|c|c|c|} 
Kr-Wallis & WT & DM & TM \\
\hline MP & 0.750 & $<0.001$ & 0.039 \\
\hline WT & & $<0.001$ & 0.051 \\
\hline DM & & & $<0.001$ \\
\hline
\end{tabular}

Fig. 2 PGRMC1 phosphorylation status affects motility and invasion. a DM cells exhibit enhanced motility in a scratch assay. Representative results for the scratch assay after $36 \mathrm{~h}$ of cell migration. Cells in the boxed area of the scratched void area for each image were counted. b Scratch assay cell migration results. Box plots of cell migration into the scratch void box areas depicted in (A) for multiple replicates. $n=12$ (MP), or 4 replicates each of sublines $1-3$ for WT and TM $(n=3 \times 4=12)$. The table shows the results of 1 way ANOVA with post-hoc Dunnet's T3 $p$-values. Video files of cell migration are available in File S1. c DM cells exhibit reduced invasion in Geltrex invasion assay. Representative images of crystal-violet stained cells in the lower surface of the transwell insert. $\mathbf{d}$ Boxplots of invasion assay results from (C) for replicates, as produced by SPSS software. $n=30$ (MP), or 10 replicates each of sublines $1-3$ for WT and TM $(n=3 \times 10=30)$. The table shows the Kruskal-Wallis $p$-values for pairwise comparisons

Many of the above proteins were inversely regulated in the comparison of WT and DM cells (Fig. 3). The energy metabolizing suite of proteins and some proteins associated with translation were less abundant in DM, whereas the T-complex chaperone complex as well as some nuclear exportins and importins were elevated in DM cells (Fig. S1D-E). Some differentially enriched pathways were specific for the WT vs. DM comparison. Different enzymes associated with heme metabolism were both up- and down-regulated while enzymes associated with glycosaminoglycan metabolism were up-regulated in WT relative to DM (Fig. 3, File S6).

Mitochondrial proteins accounted for a large percentage of the proteins more abundant in WT than DM cells. Intriguingly, many cytoplasmic proteins were more abundant in WT cells than DM (Fig. 3, File S6). We also noted higher abundance components of ATP synthase in WT and TM cells (Fig. S1C), changes of proteins 


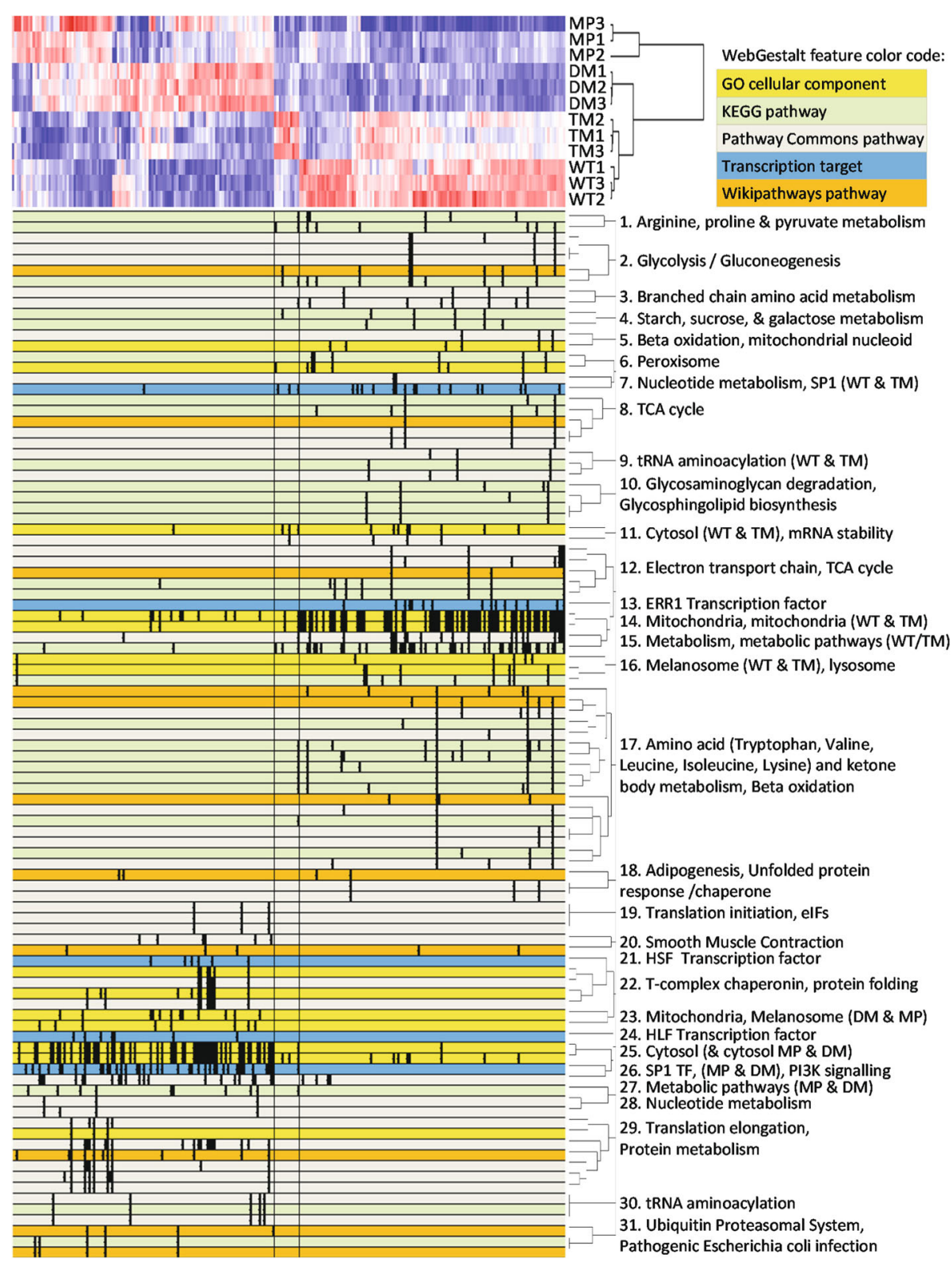

Fig. 3 Pathways analysis of SWATH-MS proteomics results. Pathways significantly enriched at the adjP>0.001 level between all 6 comparisons of "red" and "blue" differential proteins (red = higher abundance, blue = lower abundance, white = equal abundance). Top left: the proteomic heat map of 243 significantly differential proteins. A color code for WebGestalt pathways is given at top right. Bottom: WebGestalt pathways mapping. This image is derived from File S6, which contains all protein and WebGestalt pathway identities

involved in chaperonin and microtubule function (Fig. S1D), and a group of proteins involved in major histocompatibility complex antigen processing and presentation, and proteolysis (Fig. S1F). The latter are reduced in DM cells and may be associated with their reduced invasiveness (Fig. 2c-d), which requires future confirmation.

Consideration of the extreme (highest and lowest abundance) differential proteins for each cell type offers useful insight into biology (Fig. S2). WT and TM cells exhibited overlap in the subset of most abundant proteins, which included PSIP1 transcriptional coactivator, TOM40 mitochondrial import channel, as well as CDIPT which catalyzes the biosynthesis of phosphatidylinositol (circles in Fig. S2). One of the WT abundant proteins was phosphofructokinase (UniProt P08237), which catalyzes the rate limiting reaction and first committed step of glycolysis. The most abundant DM proteins included keratin 19, ubiquitin-associated protein 2-like, which is involved in stem cell maintenance [40], and methyl-CpG-binding protein 2 , which 


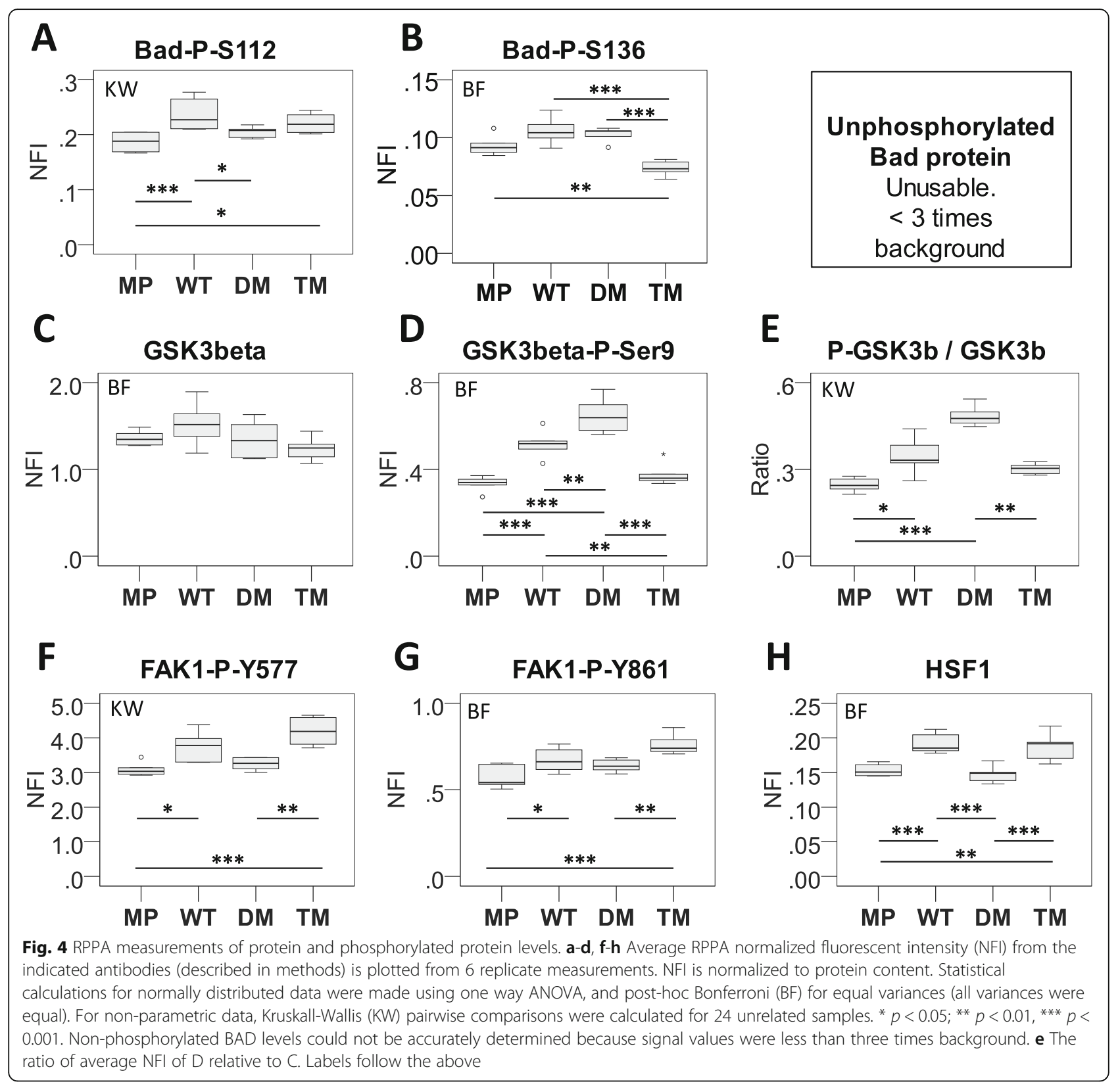

was more abundant in WT and TM cells, suggesting PGRMC1-mediated changes in genomic methylation (see accompanying paper [36]). The least abundant proteins shared a surprising mixed overlap between cell types (triangles in Fig. S2). TM and WT cells shared low levels of Ephrin type-A receptor 2, a tyrosine kinase receptor, which was higher in DM (and MP) cells without being a top abundant protein in those cells. WT exhibited low levels of signal recognition particle $54 \mathrm{kDa}$ protein, suggesting altered translation of endoplasmic reticulum proteins, and AL1A1 retinal dehydrogenase. This was notable because both DM and TM exhibited low levels of AL1A3 NAD-dependent aldehyde dehydrogenase involved in the formation of retinoic acid, suggesting alterations in retinoic acid metabolism by mutating S57/S181. DM and TM also shared low levels of ApoC3 and ApoA1 (Fig. S2), probably reflecting common lower lipoprotein synthesis by those cells. Taken together, our proteomics analysis revealed significant differences in the abundance of enzymes involved in diverse cell processes, many of which are directly implicated in cancer biology. The resemblance of WT and TM differential proteomics profiles suggests that the DM mutation activates signaling processes that are largely dependent upon Y180. (The sole difference between DM and TM proteins is the phosphate acceptor 
oxygen of Y180). Overall, this study indicated that PGRMC1 phosphorylation status exerts higher order effects in MP cells. To assess the validity of the pathways analysis, selected enriched pathways were functionally examined, as described below.

\section{ERR1 activity is not directly affected by PGRMC1}

Some mitochondrial proteins associated with energy metabolism were predicted by pathways enrichment analysis to be regulated by estrogen receptor related 1 (ERR1) transcription factor (Fig. S3A) in the comparisons of DM cells with both WT $(\operatorname{adjP}=0.004)$ and TM $(\operatorname{adjP}=0.04)$ (File S4). Since ERR1 is a steroid receptor, we investigated any potential link between the biology of PGRMC1 and ERR1 by attenuating ERR1 levels in WT cells by shRNA. This changed cell morphology from predominantly elongated to rounded cells (Fig. S3B-D). SWATH-MS proteomics revealed that ERR1 indeed regulated genes differentially abundant between WT and DM cells observed in Fig. S3A and Fig. 3. However, PGRMC1 phosphorylation status affected the abundance of only a subset of ERR1-driven proteins.

\section{PGRMC1 phosphorylation affects PI3K/AKT signaling}

Strikingly, proteins associated with PI3K/AKT activity from Fig. 3 and File S6 were revealed by File S5 to exhibit lower abundance in TM cells (Fig. S1B) relative to MP $(\operatorname{adj} P=0.0063), W T(\operatorname{adj} P=0.0001)$ and $\mathrm{DM}(\operatorname{adj} P=$ 0.0002) cells. We assayed the phosphorylation status of two AKT substrates by Reverse Phase Protein Array (RPPA). BAD is phosphorylated by both PKA at S112 [41], and at S136 by AKT [42]. Whereas there was no significant difference between BAD S112 phosphorylation between DM and TM (Fig. 4a), phosphorylated S136 levels were lower in TM cells than in all other cells $(p<0.001$, Fig. 4 b). It was not possible to reliably quantify these levels relative to BAD itself since BAD signals were too low (not shown). One of the best attested substrates of AKT is glycogen synthase kinase 3 beta (GSK3 $\beta$ ), which is phosphorylated on S9 by Akt leading to inactivation of GSK3 $\beta$ [43]. Levels of phosphorylated GSK3 $\beta$ S9 were elevated in WT over MP cells, elevated once more by removing the inhibitory CK2 sites in the DM mutation, and reduced by the further mutation of Y180 in TM mutant cells (Fig. 4c-e). These results strengthen the model arising from pathways enrichment
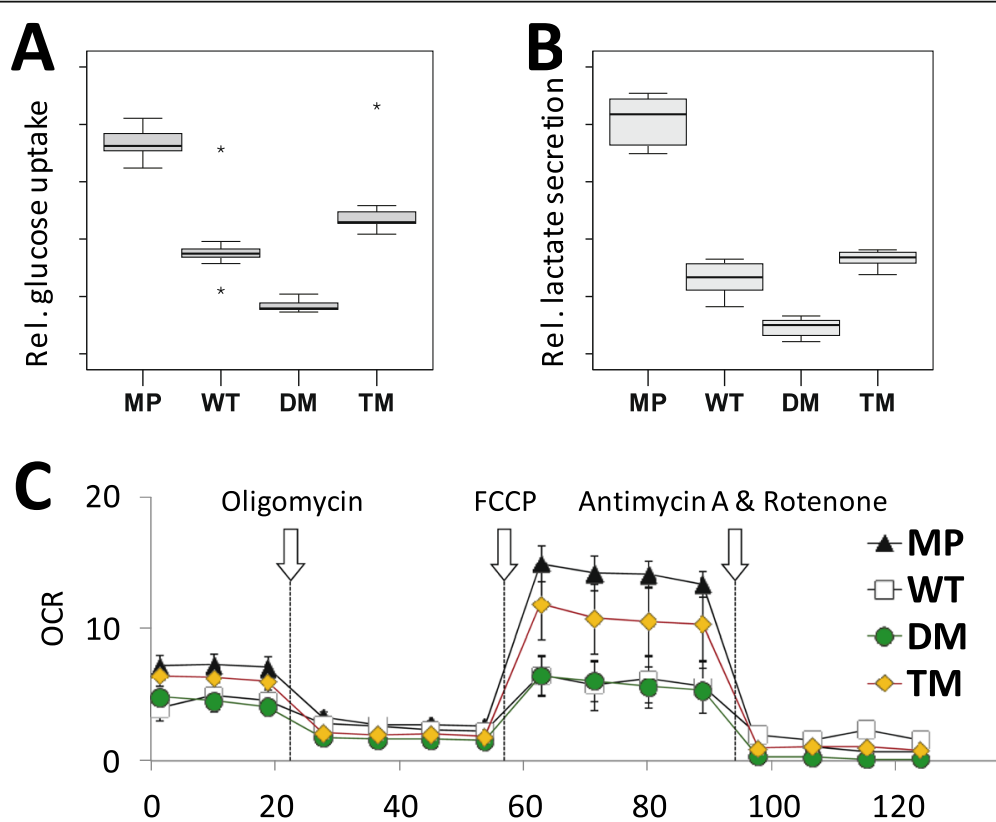

Fig. 5 PGRMC1 phosphorylation status affects glucose uptake, lactate secretion, and mitochondrial function. a Glucose uptake by cell lines using the Cayman "Glycolysis" kit. The boxplots represent four technical replicates each for each of independent stably transfected sub-lines 1-3 of each condition WT, DM and TM (lines from Fig. 1). i.e. $n=4 \times 3=12$ per condition. For MP cells, 12 replicates of the MP cell line were performed. There was significant difference between all means (Kruskal-Wallis $p<0.0001$, pairwise two-sample Kolmogorov-Smirnov Tests $p<0.0002$ ). $\mathbf{b}$ Lactate secretion by cell lines. Details follow (A), except duplicates of each stable cell line were measured $(n=3 \times 2=6$ per condition). Inter cell-type comparison tests revealed that the means of all pairwise comparisons were significantly different from one another (ANOVA, post-hoc Dunnet's $\mathrm{T} 3, p<0.003)$, except the WT-TM comparison which was not significant $(p=0.211)$. c The maximal respiratory capacity of mitochondria is affected by PGRMC1 phosphorylation status. Mitochondrial oxygen consumption of respective independent clonal stable lines $\mathrm{C1}$ of each PGRMC1-HA mutant condition WT, DM and TM. Arrows indicate the time of addition of ATP synthase inhibitor oligomycin, $\Delta \psi m$ uncoupler FCCP, and electron transport chain inhibitors rotenone \& antimycin A. OCR: oxygen consumption rate (pmol/min normalized per $\mu \mathrm{g}$ protein), $n=5$; mean $+/$ - s.d. 
analysis, that PI3K/AKT pathway which is activated in DM cells requires phosphorylated PGRMC1 Y180, and is therefore attenuated in TM cells.

\section{PGRMC1 phosphorylation affects FAK activation and HSF levels}

Pathways mapping (File S5) suggested that transcription factor HSF1 activity could be involved in the difference between WT v. DM (adjP = 0.006). HSF1 has been linked with Focal Adhesion Kinase (FAK) activity [44], and FAK activity is dependent upon Rho/ROCK signaling which influences focal adhesion dynamics and tumor cell migration and invasion [45]. RPPA measurements showed that FAK1 tyrosine phosphorylation and increased HSF1 levels were all significantly elevated in WT and TM (Fig. 4f-h). Notably, this profile resembled the differential proteomics profile of Fig. 3, rather than the ROCK-dependent rounded morphology of Fig. 1d, and once more provided validation of a pathways prediction. Notably, whereas FAK activity has been associated with increased motility [45], its phosphorylation did not differ significantly between WT and DM cells, which exhibited altered motility. Elevated FAK phosphorylation in TM cells, which exhibited lower migration than DM, could possibly be due to feedback regulation onto FAK. The basis for this merits future investigation, however presumably reflects an impingement of PGRMC1 phosphorylation status on the migratory process.

\section{Vinculin elevated in DM is required for cell motility}

Proteins of the actin cytoskeleton were more abundant in DM cells (Fig. S4A), one of which was vinculin (Fig. S1B), an actin filament-binding protein associated with cell differentiation status, locomotion, and PI3K/AKT, E-cadherin, and $\beta$-catenin-regulated WNT signaling in colon carcinoma [46, 47]. We attenuated vinculin levels in MP, WT, and DM cells via shRNA. Scrambled shRNA control (shScr) DM cells exhibited elevated scratch assay motility relative to MP cells. However in anti-vinculin shRNA (shVCL) cells, both MP and DM cell motility was reduced (Fig. S4). These results are consistent with elevated levels of proteins involved in the actin cytoskeleton (Fig. S4A) contributing directly to the enhanced motility of DM cells (Fig. 1f-g). However, that hypothesis remains untested except for vinculin. Future studies should examine the effect of PGRMC1 signaling on actin cytoskeleton properties.

\section{PGRMC1 affects glucose metabolism}

Figure 3 predicted altered glycolysis activity, which we investigated by glucose uptake and lactate production assays. Expression of all PGRMC1-HA proteins (WT, DM, and TM) led to significantly lower levels of both measures relative to MP, with DM cells exhibiting the lowest levels (Fig. 5a-b). It is unclear whether the MP/WT difference is due to PGRMC1-HA expression or to the hygromycin selection of WT cells. However, for the other cells PGRMC1 phosphorylation status regulates both features, consistent with recently reported regulation of Warburg metabolism by PGRMC1 [25], which our data indicates can be regulated by PGRMC1 phosphorylation status.

\section{PGRMC1 phosphorylation affects mitochondrial function}

Figure 3 also implied that mitochondria may be affected by PGRMC1 phosphorylation status. Naphthalimideflavin redox sensor 2 (NpFR2) is a fluorophore targeted to the mitochondrial matrix. Its fluorescence is elevated approximately 100 -fold when oxidized, providing an assay for mitochondrial matrix redox state [48]. NpFR2 revealed that the matrix of WT and TM cells was more oxidizing than MP and DM cells (Fig. S5A, B), which corresponded with the elevated expression of many nuclear-encoded mitochondrial proteins in Fig. 3.

We then examined mitochondria using the fluorescent marker MitoTracker, whose affinity for mitochondria is affected by mitochondrial membrane potential $(\Delta \psi \mathrm{m})$ [49]. Flow cytometry revealed the presence of two populations of MitoTracker-binding cells in each cell type: low and high MitoTracker-binding (Fig. S5C-E). These populations were about equal for MP, WT, and TM cells, however, DM cells exhibited overall lower relative fluorescence level in each population Fig. S5C-D) and a higher proportion of cells with higher MitoTracker binding (Fig. S5C,E). Notably, higher levels of mitochondrial proteins in WT and to some extent TM cells apparently did not correspond with higher $\Delta \psi \mathrm{m}$ caused by actively respiring mitochondria.

Relative to MP cells, the maximal respiratory rate was reduced (between 2 and 3 fold in Fig. 5c) by expression of DM or WT PGRMC1-HA, but not TM cells (Fig. 5c). The relative profiles of basal (Fig. S5F) and maximal (Fig. S5G) respiratory rates for WT and DM cells were similar, with TM cells exhibiting rates intermediate to those of MP. This profile was observed on three independent comparisons WT/DM/TM. The single experiment including MP is shown. We conclude that the altered abundance of mitochondrial proteins due to PGRMC1 phosphorylation status detected in Fig. 3 was accompanied by altered mitochondrial function. However, the relationship is not as simple as lower glucose uptake being associated with higher mitochondrial oxygen consumption, or NpFR2 redox status (a function of the rates of superoxide leakage from complex IV, and antioxidant defense systems [50]) and may involve alterations in mitochondrial permeability to protons or other uncoupling mechanisms, for instance by 

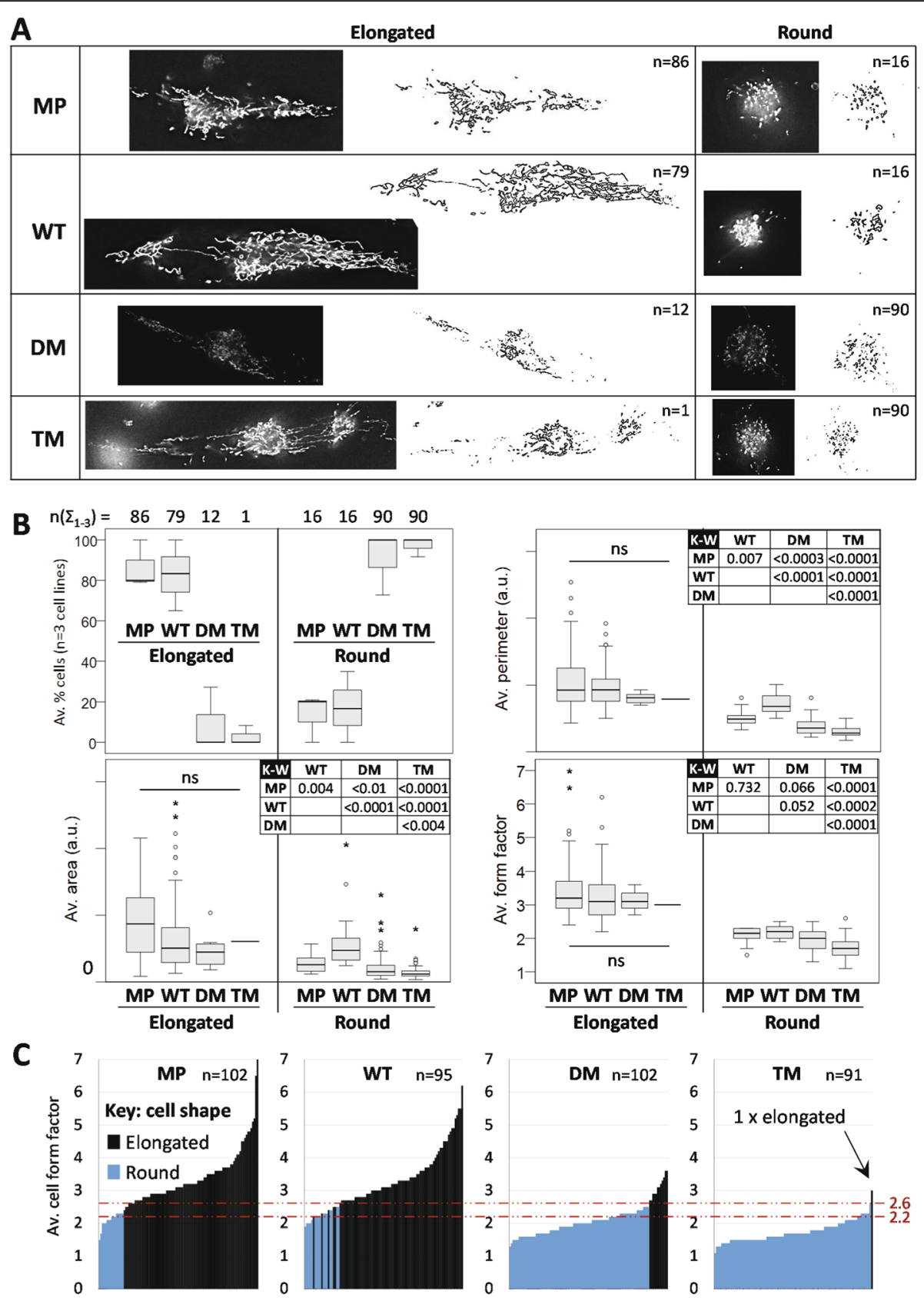

Individual cell values

Fig. 6 PGRMC1 phosphorylation influences mitochondrial and cell morphology together. a Images show cells with close to average form factor (avFF) values for elongate or rounded cells of each cell type. The numbers of cells scored in each class are indicated. All cell images are reproduced to the same scale. b Elongated and round cells from (a) examined according to cell type. The top left panel shows average percentage elongated cells scored for three independent biological replicate cell lines per cell type across all 3 replicates $\left(n\left(\Sigma_{1-3}\right)\right)$ corresponding to the given $n$ values in $(A)$. The remaining panels showing the distribution of cells in each shape and type category of Area, Perimeter and FF. Kruskal-Wallis analysis revealed no significant differences at the $p<0.05$ level between any elongated cell type comparisons (ns), whereas all cell types exhibited significant differences for round cells (Kruskal-Wallis, $P<0.001$ ). The accompanying Kruskal-Wallis post-hoc pairwise comparison $p$-values for round cells are given in the respective Tables. $\mathbf{c}$ AvFF per cell plotted including cell shape. The values where cells transition between round and elongated morphology (avFF 2.2-2.6) are indicated by dotted lines

altered cholesterol content [21], and/or altered electron transport chain properties. This result clearly reveals an important area requiring further study that was revealed by our proteomics study.
PGRMC1 phosphorylation affects mitochondrial morphology and function

Mitochondria were further explored by measuring mitochondrial content (area per cell), size (perimeter), and 
morphology, or form factor (FF). FF is a parameter derived from individual mitochondrial area and perimeter, where higher values correspond to a greater degree of filamentous than fragmented mitochondria [51, 52]. Representative images of mitochondria are shown in Fig. 6a. Numbers of mitochondria per cell varied greatly, with no significant differences detected between cell types (not shown). Over the entire data set, elongated cells exhibited greater mitochondrial area, larger mitochondria, and greater average FF (avFF) (KolmogorovSmirnov $p<0.0001$; not shown). When analyzed according to PGRMC1 status (cell type), MP and WT cells were predominantly elongated, and DM and TM were predominantly rounded, as expected (Fig. 6a-b). We detected no significant differences in average mitochondrial area, perimeter or avFF between cell types for elongated cells, however rounded cell types exhibited significant differences between the cell types for area, perimeter, and avFF (Fig. 6b). All cells with avFF $<2.2$ exhibited rounded cell shape, while all cells with avFF $>2.6$ exhibited elongated shape (Fig. 6c). The observed avFF-associated transition from round to elongated cell shape was discrete for all cells except WT, occurring at $\mathrm{avFF}=2.4(\mathrm{MP}), 2.2-2.6(\mathrm{WT}), 2.7(\mathrm{DM})$ and $2.6(\mathrm{TM})$. Notably, the single elongated TM cell also exhibited the highest avFF value for TM (Fig. 6c). Holo-tomographic time-lapse videos [53] for each cell type show live mitochondria (File S7). PGRMC1 phosphorylation status probably influences mitochondrial content, size, and FF (degree of filamentation) by the same mechanisms that affect cell shape, consistent with the proposed influence of cytoskeleton on mitochondrial morphology and function [54]. We conclude that our proteomics pathways analysis revealed biologically relevant functional differences in mitochondria, once more indicating a new area that requires further research.

\section{PGRMC1 Y180 is required for subcutaneous mouse xenograft tumor growth}

No significant differences in cell proliferation between cell types were observed in culture IncuCyte imaging (Fig. 7a), or repeated MTT assays (not shown). We established subcutaneous xenograft tumors in replicate mice carrying each of sub-lines 1-3 of WT, DM and TM (e.g. 4x line 1, 3x line 2, 3x line 3, $n=13$ per PGRMC1-HA condition), as well as $n=5$ mice with cells expressing the single Y180F mutant [24], or MP cells. Tumors produced by both TM and Y180F cells were significantly smaller than those produced by WT or DM cells (Fig. 7b-c), indicating that PGRMC1 Y180 was required for optimal tumor growth, and demonstrating that the cellular responses to altered PGRMC1 phosphorylation strongly influences cancer biology. All WT, DM, TM and Y180F tumor tissue expressed the

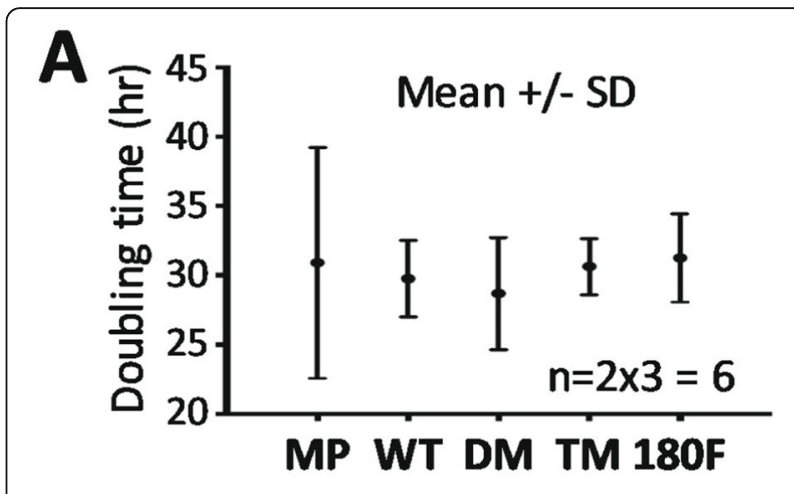

B

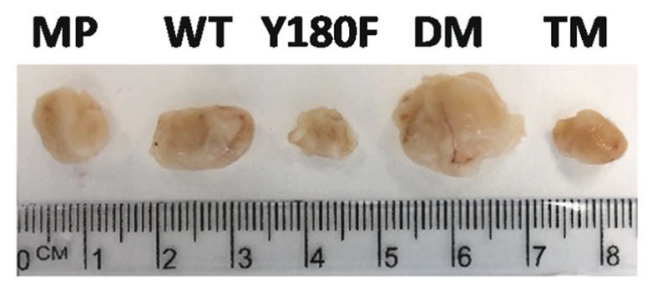

C

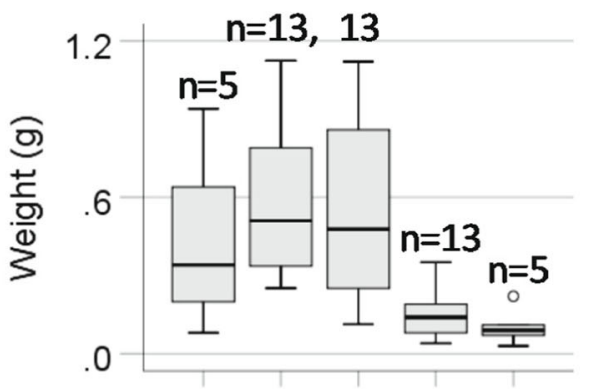

MP WT DM TM Y180F

(C) ANOVA (F>7.32, $p<0.0005$ ) Post-hoc Dunnet's T3 p values:

\begin{tabular}{|c|c|c|c|c|}
\hline C & WT & DM & TM & Y180F \\
\hline MP & 0.992 & 0.993 & 0.564 & 0.455 \\
\hline WT & & $>.999$ & $<0.0011$ & $<0.0005$ \\
\hline DM & & & $<0.010$ & $<0.005$ \\
\hline TM & & & & 0.948 \\
\hline
\end{tabular}

Fig. 7 PGRMC1 Y180 contributed to growth of subcutaneous mouse xenograft tumors. a There are no differences in cell doubling time in culture. Replicates of stable cell lines 1-3 for each condition were measure to give $n=6$. There were no significant differences between cell conditions. $\mathbf{b}$ Typical tumors produced by each respective class of cell. c Box plot of the distribution of tumor sizes among mice injected with $2 \times 10^{6}$ cells of each of the cell lines. For WT, DM and TM the results depict $4 x$ each of lines 2 and 3 , and 5 mice from line 1. MP and Y180F each represent 5 replicates of a single cell line. The box shows pairwise post-hoc Dunnet's T3 $p$-values after one way ANOVA

PGRMC1-HA proteins (not shown), and therefore arose from the injected cells. There were no obvious differences in histology between cell types based upon hematoxylin and eosin staining (not shown). 


\section{Discussion}

We report new biology associated with the phosphorylation status of PGRMC1-HA proteins from Fig. 1a, which profoundly affected cell morphology and migratory behavior. The morphotypic change from WT to DM resembled MAT in MP cells, being sensitive to ROCKI (Fig. 1d). The DM and TM altered morphology is dependent upon activated ROCK, which leads to stiffening of cortical actomyosin [55]. In human glioma cells over-expression of CD99 is implicated in MAT, resulting in rounded morphology, increased Rho activity, and enhanced migration [56]. These properties superficially resemble the phenotype of our DM cells (Fig. 1e-f), however DM cell migration involved pseudopodia and cell adhesion, as evidenced in cell migration videos (File S1). Very little else is known at the molecular level about the events that promote MAT and altered cell motility [57-60]. We provide here a global proteomics expression study of a possibly MAT-related process, and show that PGRMC1 phosphorylation status dramatically affects cell morphology and behavior.

Proteomics pathways enrichment analysis suggested that PGRMC1 also influenced mitochondria, leading us to detect altered function and morphology (Fig. 6). It was previously shown that PGRMC1 co-evolved with a suite of mitochondrial proteins [21]. The elongated cell morphology that predominated in MP and WT cells was associated with a higher index of filamentous rather than fragmented mitochondria. Cells with rounded morphology and more fragmented mitochondria predominated in DM and TM cells (Fig. 6). Such changes in mitochondrial function are driven by altered relative rates of mitochondrial fission and fusion, leading to mitochondrial fragmentation or elongated hypertubulation, respectively [61]. Fragmented mitochondria are associated with pathological conditions including cardiovascular and neuromuscular disorders, cancer, obesity, and the process of aging, associated largely with altered cell differentiation [61]. One of the proteins more abundant in WT and TM cells was Opa1 (O60313) (File S6), a protein known specifically to regulate mitochondrial fission/fusion, and one that has been reported to interact directly with PGRMC1 [62]. This suggests areas of future research.

The strongest driver of mitochondrial morphology appears to have been cell shape, or vice versa (Fig. 6). The cytoskeleton is thought to influence mitochondrial function and morphology [54], and proteomics pathways mapping suggested cytoskeletal changes. WT cells had elevated levels of Tubulin 1alpha (Q71U36), and decreased levels of Tubulin alpha-1C (Q9BQE3), Tubulin beta-2A chain (Q13885), Tubulin beta-4B chain (P68371) (Fig. S1E) relative to DM cells. Rounded DM cells exhibited more abundant type II cytoskeletal keratin 8 (P05787), type I cytoskeletal keratin 18 (P05783), and type I cytoskeletal keratin 19 (P08727) relative to MP cells (which are epithelial markers [63]), with WT and TM cells exhibiting intermediate keratin levels (see File S6 associated with Fig. 3). These keratin abundance profiles paralleled the elevated levels of proteins in an enriched actin cytoskeleton pathway in DM cells (Fig. $\mathrm{S} 1 \mathrm{~B})$. We have recently demonstrated that many proteins related to the actin cytoskeleton are coimmunoprecipitated with PGRMC1 in MP cells [64], and that the PGRMC1 membrane-associated progesterone receptor (MAPR) family cytochrome $b_{5}$ domain contains a region of predicted coiled-coil formation that resembles regions from several myosins [22], consistent with an influence of PGRMC1 on actin-related functions and interacting with proteins that interact with myosins.

DM cells also displayed elevated levels of proteins in the $\mathrm{T}$-complex protein-1 ring complex (TRiC, also known as CCT) (Fig. S1E), which contributes to folding of proteins including actin and microtubules, and influences deregulated growth control, apoptosis, and genomic instability $[65,66]$. TRiC additionally contributes to obligatory growth/survival functions in breast [67] and liver [68] cancers. TCP1 (P17987, Fig. S1E) expression is driven by oncogenic PI3K signaling in breast cancer [67], and we observe both elevated PGRMC1-dependent PI3K/AKT activity and TRiC abundance in DM cells (Fig. S1E).

In summary, many of the mitochondrial differences observed could be attributable to altered cytoskeletal properties. However, the differential mitochondrial functions of Fig. 5 and Fig. S5 did not correspond well with cell shape, indicating that PGRMC1 also changes complex causative processes driven by more than mitochondrial morphology. In this context, we note the recent observation that PGRMC2 mediates heme shuttling to the nucleus of adipocytes, leading to altered transcription of genes encoding mitochondrial proteins [69]. It is possible that PGRMC1 exerts related effects in these cells, which merits future study.

Results depicted in Fig. 3 (as presented in File S5 and File S6) revealed that both the ATP synthase subunit beta of the F1 catalytic domain as well as the F0 proton pore domain were up-regulated in WT cells relative to DM cells (Fig. S1C). It is possible that the higher $\Delta \psi \mathrm{m}$ of DM cells is related to low levels of F0/F1 ATPase proton channels (Fig. S1C), resulting in relatively inefficient proton gradient clearance. Mitochondrial cholesterol decreases the permeability of the inner membrane to protons, increasing the efficiency of electron transport chain yield [21]. Altered metabolism could be due to activity of the PI3K/AKT pathway, suggesting direction for further work that will be required to explain the mechanisms underlying the observed responses.

Loss of PGRMC1 affects the SREBP-1/fatty acid homeostasis system [70], and PGRMC1 influences cell 
surface localization of insulin receptor and glucose transporters [27]. Chemical proteomics showed that PGRMC2 but not PGRMC1 promotes adipogenesis in 3 T3-L1 preadipocytes following a gain of function interaction with a novel small molecule which displaced heme [71]. It will be interesting to examine whether that treatment mimics the effects of phosphorylation. (PGRMC2 possesses cognates to PGRMC1 Y180 and S181, as well as heme-chelating Y113 [20].)

Our results indicate that PI3K/AKT signaling in DM cells required PGRMC1 Y180, which was the sole difference to TM cells. PGRMC1 has long been recognized as a modulator of AKT activity, with cell type-specific effects $[24,27,72-76]$. This predicted activation of signals by removal of the putative inhibitory CK2 consensus sites in the DM protein $[19,24]$ was dependent upon Y180 because TM (which differs from DM by a single oxygen atom) exhibited a protein expression profile that was more similar to WT than DM (Fig. 3). Furthermore, our in vivo studies evaluating the growth of subcutaneous tumors confirmed the importance of Y180 in an intact biological system thus supporting and extending our in vitro observations to reveal the central importance of Y180 (Fig. 7). Because of the high conservation of Y180 in eumetazoan animals [22], these results are likely to bear relevance to other species, and multiple human diseases [2]. In a methylomics study of these cells in the companion paper, the most significantly down-regulated KEGG pathway in the TM/DM comparison was PI3KAKT [36], consistent with PI3K/AKT activation requiring PGRMC1 Y180, which was required for tumor growth (Fig. 7).

Interestingly, PGRMC1 knockdown in human pluripotent stem cells (hPSCs) led to an increase in GSK3 $\beta$ inhibitory phosphorylation [77]. Examination of PGRMC1 phosphorylation status in that system is merited, where PGRMC1 suppressed the p53 and WNT pathways to maintain hPSC pluripotency. Similarly to our results, those authors concluded "that PGRMC1 is able to suppress broad networks necessary for multi-lineage fate specification." Our hypothesis suggests that PGRMC1 Y180 phosphorylation and PI3K/AKT activity could be associated with elevated GSK-3 $\beta$ Ser9 phosphorylation and $\beta$-catenin signaling as observed in in some cancers [47].

Our initial hypothesis related to differential phosphorylation of PGRMC1, being potentially spatially and temporally associated with regulation of the Warburg effect [24]. It is notable that the Warburg effect resembles a reversion to stem-cell-like metabolism [78]. While this manuscript was in preparation, Sabbir showed that PGRMC1 post-translational modification status in HEK293 cells responds to P4 treatment, which was accompanied by a PGRMC1-dependent increase in glycolysis [25]. Our cells exhibited a large reduction in glycolysis between MP and WT cells, which may be due to either PGRMC1-HA expression or to hygromycin stable selection of WT cells. However phosphorylation state differences between WT, DM and TM elicited marked differences in both glucose consumption and lactate secretion (Fig. 5). It is important to note that endogenous PGRMC1 is expressed in all of these cells, and so we cannot determine to what extent these mutated proteins may elicit effects on their own, or interfere with endogenous PGRMC1. However, we conclude that PGRMC1 can modulate glycolysis, in line with our hypothesis, although the mechanism requires further research which should examine the possibility that PI3K/ AKT activity elevated in DM cells negatively regulates the Warburg effect.

\section{Conclusion}

The phospho-acceptor amino acid Y180 has been conserved in PGRMC1 proteins since the evolutionary appearance of the differentiation-inducing gastrulationorganizer [22]. We therefore believe it likely that the PGRMC1 Y180-regulated modulation of metabolic and growth control that we have manipulated could represent a major newly identified foundational axis of animal cell biology, whose perturbation is inconsistent with the maintenance of differentiated states acquired during the subsequent evolution of complex body plans.

Although we can confidently deduce the existence of a PGRMC1 signal network, as yet we have identified neither immediate upstream PGRMC1 effectors nor downstream targets. In a companion study [36], we show that the cells characterized in this paper differ dramatically in genomic methylation and mutation rates. Future studies should urgently explore the relationship between PGRMC1 signaling and diseases such as cancer, diabetes, Alzheimer's disease, and others [2].

\section{Methods \\ Plasmid preparation}

Plasmids pcDNA3.1-PGRMC1-HA (wild type: WT), pcDNA3.1-PGRMC1-HA_Y180F (Y180F), pcDNA3.1PGRMC1-HA_S57A/S181A (double mutant, DM) and pcDNA3.1-PGRMC1-HA_Y180F (Y180F) [24] have been described. The triple mutant S57A/Y180F/S181 (TM) was constructed by Genscript (Hong Kong) using the DM plasmid as the template and introducing codon TTC for F180. PGRMC1-HA open reading frames were reconfirmed by DNA sequencing at Monash Micromon DNA Sequencing Facility (Clayton, Vic., Australia) using the $5^{\prime} \mathrm{T} 7$ and 3' $\mathrm{BGH}$ sequencing primers specific for the parental vector. PGRMC1-HA plasmids were transformed into Escherichia coli Top10 strain, and cultured overnight at $37^{\circ} \mathrm{C}$ on $1 \%$ agar plates containing Luria broth (LB) media (Invitrogen) and $50 \mu \mathrm{g} / \mathrm{mL}$ ampicillin. 
A single colony was picked and bacteria were grown in $250 \mathrm{ml}$ culture by aeration overnight at $37^{\circ} \mathrm{C}$ in $\mathrm{LB}$ media. Plasmid DNA was isolated by GeneJet Maxiprep Kit (ThermoScientific) following the manufacturer's protocol. Plasmid DNA concentration was measured by using Nanodrop (Thermo Scientific).

\section{Cell culture}

MIA PaCa-2 (MP) cell identity was verified as MIA PaCa-2 (ATCC CRL-1420) by the MHTP Medical Genomics Facility (Monash University, Melbourne) following the ATCC Standards Development Organization document ASN-0002 for cell line identification via short tandem repeat profiling. MP cells were maintained in Dulbecco's Modified Eagle's medium (DMEM-high glucose, Sigma-Aldrich, D5796) supplemented with $10 \%$ Foetal bovine calf serum (SigmaAldrich, F9423) and 1\% penicillin-streptomycin (Sigma-Aldrich, P4333) (complete DMEM) at $37{ }^{\circ} \mathrm{C}$ and $5 \% \mathrm{CO} 2$ in a 150i $\mathrm{CO}_{2}$ incubator (Heracell, Lane Cove NSW). Cell doubling times were estimated by 3-(4,5-dimethylthiazolyl-2)-2, 5-diphenyltetrazolium bromide (MTT) assay or by IncuCyte, as described [79]. Mitochondrial respiratory capacity was measured using a Seahorse Extracellular Flux analyzer XF24 (Seahorse Biosciences).

\section{Transfection and stable cell line generation}

Under our culture conditions, MP cells exist in culture as flattened adherent cells of mesenchymal shape, a minority of rounded adherent cells, and a small population of rounded suspension cells. Plating the suspension cells regenerates a similar population distribution (not shown). On the day before transfection, $2 \times 10^{6} \mathrm{MP}$ cells were seeded onto a 6 -well plate. The cells were transfected at $70-80 \%$ confluency. Before transfection, cells were washed with Dulbecco's phosphate-buffered saline (PBS, Sigma-Aldrich, D8537) and maintained in antibiotic-free Dulbecco's Modified eagle Medium high glucose (DMEM, Sigma-Aldrich, D5796) containing 10\% bovine calf serum (Sigma-Aldrich, 12133C) and 1\% penicillin/streptomycin (Sigma-Aldrich, P4458) (complete DMEM). In separate transfections, $4 \mu \mathrm{g}$ each of respective PGRMC1-HA plasmids (WT, DM or TM) and Lipofectamine 2000 (Life Technologies, 11,668-019) were mixed at 1:2 ratio and incubated for $25 \mathrm{~min}$ at room temperature. The mixture was then added drop-wise to the wells of the culture plate. After $6 \mathrm{~h}$ of incubation, cells were washed with PBS and cultured at $37^{\circ} \mathrm{C}$ and $5 \% \mathrm{CO}_{2}$ in complete DMEM for $48 \mathrm{~h}$, after which cells were harvested and plated in three fold limiting dilution in complete DMEM containing $50 \mu \mathrm{g} / \mathrm{ml}$ Hygromycin B (EMD Millipore, 400,052) in 96 well plates. Cells were cultured at $37{ }^{\circ} \mathrm{C}$ and $5 \% \mathrm{CO} 2$ for 2 weeks, with regular media changes containing complete DMEM with Hygromycin B every 3 days to select for stable integration events. Typically 8 independent stably transfected cell lines were expanded for each of PGRMC1-HA WT, DM and TM and 3 lines with similar levels of PGRMC1-HA expression were selected by Western blot.

Cells were frozen $0.5-1.0 \mathrm{~mL}$ at $-80^{\circ} \mathrm{C}$ in Bambanker (Novachem, \#306-14,684) at $2 \times 10^{6}$ cells $/ \mathrm{mL}$. Frozen cells were introduced back into culture by thawing at $37^{\circ} \mathrm{C}$ for $20 \mathrm{~s}$ followed by addition to $5 \mathrm{ml}$ of complete media and low speed centrifugation at $180 \mathrm{x}$ g for 3 mins at $25^{\circ} \mathrm{C}$. Pelleted cells were resuspended in $6 \mathrm{~mL}$ fresh complete media and seeded in $25 \mathrm{~cm}^{2}$ flasks.

Because of the dramatic effects observed, MP cells are included in our experiments as a literature reference point. MP differ from WT cells by not having undergone hygromycin selection, and by lack of overexpression of PGRMC1-HA. Therefore we cannot ascribe differences between MP and WT cells to PGRMC1-HA expression. The effects of the DM and TM PGRMC1 mutations are assessed relative to WT control levels.

\section{shRNA lentiviral production}

Lentiviral-delivered shRNAs were constructed using Mission TRC2-pLKO-Puro series lentiplasmids (SHCLND, Sigma-Aldrich) targeting ERR1/ESRRA (TRCN0000330191, GAGAGGAGTATGTTCTACTAA), vinculin (shVCL) (TRCN0000290168, CGGTTGGTACTGCTAATAAAT) or non-target scrambled shRNA (shScr) (SHC202; CAACAAGATGAAGAGCACCAA). MP and DM shVCL cells were obtained at first attempt, however, despite three attempts, WT cells could not be established. To generate virus particles, we co-transfected HEK293 cells with the shRNA plasmids and helper plasmids using Lipofectamine 2000 (Invitrogen, 11668-027). Prior to transfection, 6 well plates were treated with $50 \mu \mathrm{g} / \mathrm{mL}$ D-Lysine overnight. Next day, $1 \times 10^{6}$ HEK293 cells were seeded per well and incubated overnight at $37^{\circ} \mathrm{C}$ in complete medium. Transfection mixture A contained $4 \mu \mathrm{g}$ plasmid mixture consisting of $2.5 \mu \mathrm{g}$ target or shScr shRNA lentiplasmid, $0.75 \mu \mathrm{g}$ Pax, $0.3 \mu \mathrm{g}$ Rev. and $0.45 \mu \mathrm{g}$ VSV-G helper plasmids [80] in $250 \mu \mathrm{L}$ antibiotic-free medium. Transfection mixture B contained $8 \mu \mathrm{L}$ Lipofectamine and $242 \mu \mathrm{L}$ antibiotic-free medium. After 5 min incubation at $25^{\circ} \mathrm{C}$, mixtures $\mathrm{A}$ and B were gently mixed and incubated for $25 \mathrm{~min}$ at $25^{\circ} \mathrm{C}$. HEK293 culture medium was removed, cells were washed with PBS, and $2 \mathrm{~mL}$ fresh antibiotic-free medium was added followed by addition of combined transfection mixture to the cells, dropwise with gentle shaking, followed by incubation for $6 \mathrm{~h}$ at $37^{\circ} \mathrm{C}$. After incubation, the medium was replaced with complete medium overnight at $37^{\circ} \mathrm{C}$. Virus particles were harvested by collecting culture medium followed by the addition of new medium every $24 \mathrm{~h}$ for $72 \mathrm{~h}$. Collected media for each culture were pooled, filtered through a $22 \mu \mathrm{M}$ filter, aliquoted into $1 \mathrm{~mL}$ fractions, and frozen at $-80^{\circ} \mathrm{C}$. 


\section{shRNA lentiviral transduction}

Briefly, $1 \times 10^{5} \mathrm{MP}$, WT, or DM cells per 24 plate well were seeded in $1 \mathrm{~mL}$ complete DMEM medium and grown to $60 \%$ confluency. The medium was removed, and replaced by $1 \mathrm{~mL}$ of medium per well, containing 2fold serially diluted virus particles in adjacent wells, plus $5 \mu \mathrm{g} / \mathrm{mL}$ Polybrene (hexadimethrine bromide, SigmaAldrich 107689) to enhance viral transduction. After incubation for $24 \mathrm{~h}$, the medium was removed and the cells were washed twice with PBS after which fresh medium was added supplemented with $1.5 \mu \mathrm{g} / \mathrm{mL}$ Puromycin, which was replaced every $48 \mathrm{~h}$ for 1 week. Cells from wells transduced with the lowest dilutions of respective virus particles that survived selection were expanded, and stocks frozen at $-80{ }^{\circ} \mathrm{C}$ in Bambanker.

\section{Scratch migration assay}

MP cells or stable transfected monoclonal MP cell lines expressing PGRMC1-HA WT, DM or TM proteins $(1 \times$ $10^{4}$ cells) were seeded in a 24 well plate. The monolayer of cells at more than $90 \%$ confluency was subjected to serum starvation for $2 \mathrm{~h}$. A scratch was created in the middle of the monolayer by a sterile p200 tip and washed twice with PBS to remove floating cells. Complete media was then added. The cell monolayer was incubated for 36 $\mathrm{h}$ to allow cell migration into the scratched area. Photographic images were taken at 0 and $36 \mathrm{~h}$ using an inverted phase microscope (Nikon Eclipse Ti-U). Cells in the boxed areas of Fig. 2a were manually scored from printed images. Cell treatments included $125 \mathrm{nM}$ Y-27632 dihydrochloride (Abcam, ab120129, Rho Kinase inhibitor: ROCKI) or vehicle control (DMSO). For video files the cells were incubated at $37^{\circ} \mathrm{C}$ and $5 \% \mathrm{CO}_{2}$ for $36 \mathrm{~h}$ in a stage top electrically heated chamber (Okolab H301-NIKONNZ100/200/500-N) including transparent heated lid (H301-EC-HG-LID), with a 24-well Nunc/Greiner plate base adapter (24 MW-NUNC) and a chamber riser, for a working distance of $28 \mathrm{~mm}$. The chamber was regulated by a Control Unit (Okolab H301-TC1-HMTC) with Digital $\mathrm{CO}_{2}$ controller (Okolab DGT-CO2 BX) and Air Pump (Okolab, OKO-AP) and was inserted to a NanoZ100-N Piezo stage (Mad City Labs) on a motorized XY stage (Nikon TI-S-ER). Images were taken every $10 \mathrm{~min}$ for $36 \mathrm{~h}$ with a $10 \times(0.45 \mathrm{NA})$ Plan Apo objective using the transmitted light detector (TD) on a Nikon Ti Eclipse Confocal microscope controlled by NIS Elements V4.10 software (Nikon).

\section{Proteomics sample preparation}

Three independent stable transfected lines of each PGRMC1-HA-expressing cell type, as well as triplicates of the MP parental cell line, were measured in technical replicate data-dependent and independent data acquisition SWATH-MS modes on a 5600 TripleTof $^{\text {in }}$ mass spectrometer (ABSciex). Global proteomics analysis was carried out at the Australian Proteome Analysis Facility (APAF). Cells were grown in Wagga Wagga to $80 \%$ confluency in $75 \mathrm{~cm}^{2}$ flasks. Three separate cultures of MP cells (passages 8, 9 \& 11) and three lines of each PGRMC1-HA WT, DM and TM cells were used (independent biological triplicates). Cells were harvested and frozen cell pellets shipped on dry ice to APAF for Mass spectrometric analysis. Cell pellets were lysed using $200 \mu \mathrm{L}$ of sodium deoxycholate buffer $(1 \%$ in $0.03 \mathrm{M}$ triethyl ammonium bicarbonate), and DNA digested using $0.5 \mu \mathrm{g}$ of benzonase. Direct detect assay (EMD Millipore, DDAC00010-8P) was performed on the samples and $100 \mu \mathrm{g}$ of each sample was taken for digestion. Samples were reduced with dithiothreitol $(5 \mathrm{mM})$, alkylated with iodoacetamide $(10 \mathrm{mM})$ and then digested with $4 \mu \mathrm{g}$ trypsin for $16 \mathrm{~h}$ at $37^{\circ} \mathrm{C}$. The digested sample was acidified and centrifuged to remove the sodium deoxycholate. Samples were then dried and resuspended in $100 \mu \mathrm{L}$ of loading buffer ( $2 \%$ acetonitrile $0.1 \%$ formic acid). Individual samples for SWATH analyses were diluted 1:4 into loading buffer and transferred to a vial. Each sample was measured in technical replicate. For IDA runs a pool was made for each group (MP, WT, DM, and TM) by taking equal portions from each biological replicate and diluting 1:4 in loading buffer.

\section{Proteomic information dependent acquisition}

Tryptic peptides were analyzed on a 5600 TripleTof $^{\text {in }}$ mass spectrometer (ABSciex). Chromatographic separation of peptides was performed on a NanoLC-2Dplus HPLC system (Eksigent, Dublin, CA) coupled to a selfpacked analytical column (Halo C18, $160 \AA$, $2.7 \mu \mathrm{m}$, $75 \mu \mathrm{m} \times 10 \mathrm{~cm})$. Peptide samples $(4 \mu \mathrm{g}$ of total peptide amount) were loaded onto a peptide trap (Opti-trap Cap $0.5 \mathrm{~mm} \times 1.3 \mathrm{~mm}$, Optimize Technologies) for preconcentration and desalted with $0.1 \%$ formic acid, $2 \%$ acetonitrile, at $10 \mu \mathrm{L} / \mathrm{min}$ for $5 \mathrm{~min}$. The peptide trap was then switched into line with the analytical column and peptides were eluted from the column using linear solvent gradients with steps, from $98 \%$ Buffer A $(0.1 \%$ formic acid) and 2\% Buffer B (99.9\% acetonitrile, 0.1\% formic acid) to $90 \%$ Buffer A and 10\% Buffer B for 10 min, then to $65 \%$ Buffer A and $35 \%$ Buffer B at $500 \mathrm{~nL} /$ min over a 78 min period. After peptide elution, the column was cleaned with $95 \%$ Buffer B for 15 min and then equilibrated with $98 \%$ Buffer A for 15 min before the next sample injection. The reverse phase nanoLC eluent was subject to positive ion nanoflow electrospray analysis in an IDA mode. Sample analysis order for LC/MS was DM1, DM2, DM2, DM3, DM3, MP2, MP2, MP3, MP3, TM2, TM2, TM3, TM3, WT1, WT1, WT2, WT2, WT3, WT3, DM1, MP1, MP1, TM1, TM1. 
In the IDA mode a TOFMS survey scan was acquired $(\mathrm{m} / \mathrm{z} 350-1500,0.25 \mathrm{~s})$, with the 10 most intense multiply charged ions $(2+-5+$; counts $>150)$ in the survey scan sequentially subjected to MS/MS analysis. The selected precursors were then added to a dynamic exclusion list for 20s. MS/MS spectra were accumulated for 50 milliseconds in the mass range $\mathrm{m} / \mathrm{z} 100-1500$ with rolling collision energy.

\section{Proteomic data independent acquisition (SWATH)}

Samples were analyzed by SWATH-MS [81] proteomics profiling in duplicate, with the chromatographic conditions as for IDA analysis above. The reverse phase nanoLC eluent was subject to positive ion nanoflow electrospray analysis in a data independent acquisition mode (SWATH). For SWATH MS, $\mathrm{m} / \mathrm{z}$ window sizes were determined based on precursor $\mathrm{m} / \mathrm{z}$ frequencies $(\mathrm{m} / \mathrm{z} 400-1250)$ in previous IDA data (SWATH variable window acquisition, 60 windows in total). In SWATH mode, first a TOFMS survey scan was acquired $(\mathrm{m} / \mathrm{z}$ $350-1500,0.05 \mathrm{~s}$ ) then the 60 predefined $\mathrm{m} / \mathrm{z}$ ranges were sequentially subjected to MS/MS analysis. MS/MS spectra were accumulated for 96 milliseconds in the mass range $\mathrm{m} / \mathrm{z}$ 350-1500 with rolling collision energy optimized for lower $\mathrm{m} / \mathrm{z}$ in $\mathrm{m} / \mathrm{z}$ window $+10 \%$. To minimize instrument condition caused bias, SWATH data were acquired in random order for the samples with one blank run between every sample.

\section{SWATH library generation}

The LC-MS/MS data of the IDA data were searched using ProteinPilot (version 4.2) (Sciex) and combined into a single search report file. The files were searched against Human entries in the Swissprot 2014_04 database (released 16/04/2015, containing 545,388 entries). The search parameters were selected as follows: iodoacetamide cysteine alkylation, trypsin digestion, Triple TOF 5600 instrumentation, biological modifications, thorough search and false discovery rate enabled.

\section{SWATH data processing}

SWATH data were extracted using PeakView (version 2.1, Sciex) with the following parameters: Top 6 most intense fragments of each peptide were extracted from the SWATH data sets $(75 \mathrm{ppm}$ mass tolerance, $10 \mathrm{~min}$ retention time window). Shared peptides were excluded. After data processing, peptides ( $\max 50$ peptides per protein) with confidence $\geq 99 \%$ and FDR $\leq 1 \%$ (based on chromatographic feature after fragment extraction) were used for quantitation. The extracted SWATH protein peak areas were normalized to the total peak area for each run and subjected to t-test to compare relative protein peak area between the samples. Protein t-test with $p$-value smaller than 0.05 and fold change larger than
1.5 were highlighted as differentially expressed. The analysis of four different cell types was treated as six separate paired comparisons: 1) MP vs. WT, 2) MP vs. DM, 3) MP vs. TM, 4) WT vs. DM, 5) WT vs. TM, and 6) DM vs. TM. Additionally, a similar method for determining differential expression was run at the peptide level, with the peptide level fold changes then averaged for each protein. The peptide level analysis is more conservative, as peptide level $p$-values are only generated when a protein was identified by at least two proteins. Peptide level data were used for this study.

\section{WebGestalt enrichment analyses}

Gene Ontology (GO) and pathway enrichment analysis were conducted on differentially abundant proteins from Figure S2D using the WEB-based GEne SeT AnaLysis Toolkit (WebGestalt) platform (http://bioinfo.vanderbilt. edu/webgestalt/) [82]. Figures or Supplementary Figures depicting or relying on WebGestalt results describe supplementary data files available online that contain the respective original WebGestalt analysis files. Attempting to identify the most important driving contributions to the phenotypic alterations observed, a complementary WebGestalt analysis was also performed at the $\operatorname{adj} \mathrm{P}<$ $0.001 \%$ level, but employing the subsets of proteins which were detected to be either significantly up- or down-regulated ("red" and "blue" lists of proteins for each comparison from File S1). The UniProt protein IDs from respective proteomics comparisons were uploaded as text files which accompany the respective WebGestalt supplementary data files. KEGG, Pathway Commons, and Wiki Pathways were analyzed at the 5\% level. GO and transcription Factor analyses were also performed for comparisons of differentially up- or down-regulated proteins for each pair-wise comparison between cell types at the 0.1 and $10 \%$ levels. The following WebGestalt settings were employed: Organism: hsapiens; gene Id Type: entrezgene; Reference Set for Enrichment Analysis; entrezgene_protein-coding; Significance Level: (variable see individual analysis descriptions), Statistical Method: Hypergeometric, Multiple Test Adjustment: Benjamini-Hochberg (BH), Minimum Number of Genes for a Category: 3.

Pathway enrichment analyses can consider either a) all differential proteins together (including both up- and down-regulated proteins in the one analysis), or b) can examine the higher abundance and lower abundance proteins in separate analyses for each comparison ("red" or "blue" analyses for each comparison). Our WebGestalt pathway analysis strategy of Fig. 3 pursued the second of these alternatives. In the first analysis, all proteins found to be differential (both up- and down-regulated) between two samples in any six of the analyses were 
entered as a protein list to WebGestalt, and pathway enrichment analysis was performed with multiple sample correction at the Benjamini and Hochberg $(\mathrm{BH})$ adjusted p (adjP) significance level of 0.001 for KEGG, Pathway Commons, and Wikipathways for each of the six basic cell-type comparisons.

Twelve separate WebGestalt analyses were performed for Fig. 3, with enrichment analyses including KEGG, PC, WikiPathways, as well as Transcription Factor and GO cellular component. The schematic representation of Fig. 3 shows pathways identified as significantly enriched for at least one of 12 comparisons (6x more abundant "red" and 6x less abundant "blue") between 1) MP vs. WT, 2) MP vs. DM, 3) MP vs. TM, 4) WT vs. DM, 5) WT vs. TM, and 6) DM vs. TM. The pathway mapping for all significantly detected features between all comparisons detected at adj $\mathrm{P}<0.001$ is available as File S5A. Another WebGestalt analysis was performed at $\operatorname{adj} \mathrm{P}<0.1$ and the significances of each pathway identified in File S5A at the adj $\mathrm{P}<0.001$ level were then recorded for all comparisons at the adj $\mathrm{P}<0.1$ level in File $\mathrm{S} 5 \mathrm{~B}$. The analysis results are presented for reference as File S4B. That information was used to assign statistical significance in the pathways map for all features that were identified at the adj $\mathrm{P}<0.001$ level in any one comparison, across all 12 comparisons at the adj $\mathrm{P}<0.1$ level. These data were then used to map all proteins from all pathways and all comparisons of File S5B to produce the original image of Fig. 3 in Microsoft Excel, which is available as File $\mathrm{S} 6$ and contains all protein and pathway identities.

\section{Mapping pathways to the expression heat map}

The matrix of protein membership to pathway or functional group category is a resulting sparse matrix with $0 /$ 1 indicating that the respective protein is/is not present in the respective category. This matrix was clustered using the hclust implementation in the $\mathrm{R}$ Base Package (www.r-project.org/), using a binary distance and complete linkage, to reorder the columns (pathways in this case) according to the proportion of shared proteins. The resulting cladogram including overlapping features identified by all WebGestalt analyses appears to the right of pathways in Fig. 3, and with complete accompanying protein and pathway identities in File S5.

\section{Principal components analysis on proteomics results}

Principal component analysis was used to examine the largest contributions to variation in the protein measurements. Wilcoxon rank-sum tests were used to identify the pathways that were positively or negatively associated with the principal component scores.

\section{Sample preparation for Western blots}

Approximately $70 \%$ confluent cells in a T75 flask were washed twice with chilled PBS buffer and incubated with $500 \mu \mathrm{L}$ radio immunoprecipitation assay buffer (RIPA buffer) (Sigma-Aldrich, R0278) supplemented with protease and phosphatase inhibitor cocktail (Thermoscientific, 88668) following manufacturer's recommendations. After scraping, the lysate was centrifuged at $8000 \mathrm{~g}$ for 20 min (Hermle Centrifuge Z233 M-2) at $4{ }^{\circ} \mathrm{C}$. Protein concentration was determined using the Pierce $\mathrm{BCA}$ protein assay kit (ThermoFisher, 23225) following the manufacturer's instructions. Twenty microgram cell lysates were each mixed with $2 x$ Laemmli loading buffer (Sigma-Aldrich, S3401) at a 1:1 ratio to give final volume $20 \mu \mathrm{L}$, followed by denaturation at $95^{\circ} \mathrm{C}$ for $5 \mathrm{~min}$ in a digital dry bath heater. Lysates were loaded immediately to a 10\% SDS-PAGE gel. For HA western we used 17 well gels (Life technologies, NW04127), for PGRMC1 Western blots we used 15 well gels (Bio Rad. 456-1069), for vinculin and ERR1 Western blots we used 10 well gels (Bio Rad 456-1096). Electrophoresis was at $150 \mathrm{~V}$ for $45 \mathrm{~min}$. Protein was transferred onto PVDF membranes (Bio-Rad, 1620174) with a Trans-Blot Turbo transfer system (Bio-Rad, Gladesville NSW) for 7 min by Trans-Blot ${ }^{\circ}$ Turbo RTA Mini LF PVDF Transfer Kit (Bio-Rad, 1704274) or wet transferred in $25 \mathrm{mM}$ Tris, $192 \mathrm{mM}$ glycine, 20\% (v/v) methanol (pH 8.3) (1x Towbin buffer) at $20 \mathrm{~V}$ for $2.5 \mathrm{~h}$ on mini trans-blot cell (Bio Rad, 1703930) cooled on ice.

\section{Western blots}

Membranes were blocked with TBS-T $(0.1 \%$ Tween-20 in $1 \times$ Tris-buffered saline) containing 5\% Woolworths Instant Skim Milk Powder (Woolworths, Wagga Wagga, NSW, Australia) for $1 \mathrm{~h}$ and incubated overnight at $4{ }^{\circ} \mathrm{C}$ with primary $\left(1^{\circ}\right)$ antibody. After washing 3 times with TBS-T, blots were incubated with secondary $\left(2^{\circ}\right)$ antibody for $1 \mathrm{~h}$ at room temperature. Proteins were detected by the following methods. For chemiluminescence detection the membranes were incubated with Clarity Max Western ECL Substrate (Bio-Rad, \#1705062) for 5 min for detection by enhanced chemiluminescence using a Bio-Rad ChemiDoc MP imaging system (Bio-Rad, Gladesville NSW). Fluorescence detection was performed on the ChemiDoc (at the indicated wavelength). Molecular weight standard proteins for gels imaged for fluorescence or chemiluminescence were detected on the ChemiDoc using the IRDy680 channel. Colorimetric detection (Vinculin and ERR1 Western blots) was performed by incubation of membranes with $3 \mathrm{~mL}$ Tetramethylbenzidine (TMB) (Sigma-Aldrich, T0565) for $5 \mathrm{~min}$. These images were captured by Molecular Imager Gel Doc XR+ System (Bio-Rad, Gladesville NSW). Multi-channel ChemiDoc images were generated 
with the Bio-Rad Image Lab Software. Some dual channels images were manipulated in Adobe Photoshop CC 2018 (Adobe Systems Inc.) by reducing intensity in either red or green channel to lower background in the published image. Adjustments were applied identically over all image pixels so as to not alter the relative intensities of any bands.

The following primary $\left(1^{\circ}\right)$ and secondary $\left(2^{\circ}\right)$ antibody pairs were used (at the specified dilutions) with the indicated detection methods. For PGRMC1 Western: $1^{\circ}$ goat anti-PGRMC1 antibody (Abcam, ab48012) (1:1000) and $2^{\circ}$ rabbit anti-goat secondary antibody (Abcam, ab6741) (1:4000) detected by chemiluminescence. After detection, membranes were blocked with TBS-T overnight and then incubated with $1^{\circ}$ mouse anti-beta actin (Sigma-Aldrich, A5541) (1:2000) and $2^{\circ}$ goat anti-mouse IgG H\&L (IRDye 800CW) (1:5000) detected by fluorescence (IRDye $800 \mathrm{CW}$ ). For HA epitope Western: $1^{\circ}$ mouse anti-HA (Sigma-Aldrich, H3663) (1:2000) and $2^{\circ}$ goat anti-mouse IgG H\&L (IRDye $800 \mathrm{CW}$ ) (dilution 1 : 5000 ) detected by fluorescence (IRDye $800 \mathrm{CW}$ ), as well as $1^{\circ}$ rabbit anti-beta-actin (Cell Signaling, 4967) (1:2000) and $2^{\circ}$ donkey anti-rabbit IgG (Abcam, ab16284) (1:2000) detected by chemiluminescence. For vinculin Western: $1^{\circ}$ anti-vinculin (E1E9V) XP (Cell Signaling Technology, 13, 901) (1:1000) and $2^{\circ}$ donkey anti-rabbit IgG (Abcam, ab16284) (1:2000) detected colorimetrically. For ERR1 Western: $1^{\circ}$ rabbit anti-ERR $\alpha$ (E1G1J) (Cell Signaling, $13826 \mathrm{~S})(1: 1000)$ and $2^{\circ}$ donkey anti-rabbit IgG (Abcam, ab16284) (1:2000) detected colorimetrically.

\section{Reverse Phase Protein Array analysis}

RPPA arrays using Zeptosens technology (Bayer AG, Leverkusen, Germany) were used for analysis of signaling protein expression and activity profiling as described [8386]. For the analysis, flash frozen cell pellets were lysed by incubation with $100 \mu \mathrm{l}$ cell lysis buffer CLB1 (Bayer, Germany) for $30 \mathrm{~min}$ at room temperature. Total protein concentrations of the lysate supernatants were determined by Bradford Assay (Coomassie Plus, Thermo Scientific). Cell lysate samples were adjusted to uniform protein concentration in CLB1, diluted 10-fold in RPPA spotting buffer CSBL1 (Bayer) and subsequently printed as series of four dilutions (starting concentration at $0.3 \mu \mathrm{g} / \mu \mathrm{l}$ plus 1.6fold dilutions) and in two replicates each. All samples were printed as replicate microarrays onto Zeptosens hydrophobic chips (Bayer) using a NanoPlotter 2 (GeSim, Grosserkmannsdorf, Germany) applying single droplet depositions $(0.4 \mathrm{~nL}$ volume per spot). After printing, the microarrays were blocked with $3 \% \mathrm{w} / \mathrm{v}$ albumin, washed thoroughly with double distilled $\mathrm{H}_{2} \mathrm{O}$, dried in a stream of nitrogen and stored in the dark at $4{ }^{\circ} \mathrm{C}$ until further use.

Protein expression and activity levels were measured using a direct two-step sequential immunoassay and sensitive, quantitative fluorescence read-out. A single array was probed for each protein. Highly specific and upfront validated primary antibodies were incubated at the respective dilution in Zeptosens assay buffer overnight (15 h) at room temperature. Arrays were washed once in assay buffer and incubated for $45 \mathrm{~min}$ with Alexa647-labeled anti-species secondary antibody (Invitrogen, Paisley, UK). Arrays were then washed as before and imaged using a ZeptoREADER instrument (Bayer) in the red laser channel. Typically, six fluorescence images were recorded for each array at exposure times of between 0.5 and $16 \mathrm{~s}$. Negative control assays incubated in the absence of primary antibody (blank assays) were also performed to measure the nonspecific signal contributions of the secondary antibody. In addition, one chip out of the print series was stained to measure the relative amount of immobilized protein per spot (protein stain assay). The following primary antibodies (provider and reagent number, dilution) were used: BAD (CST 9239, 1:200), BAD-P-Ser112 (CST 5284, 1:100), BAD-P-Ser136 (CST 4366, 1:100), FAK1-P-Tyr577 (Invitrogen 44-614ZG, 1:100), FAK1-P-Tyr861 (Epitomics 2153-1, 1:100), GSK3beta (CST 9315, 1:200), GSK3beta-PSer9 (CST 9336, 1:100), HSF1 (Epitomics 2043-1, 1:1000).

After assay measurements (one protein per array), array images and data were analyzed with the software ZeptoVIEW 3.1 (Bayer). For each array/antibody, the image taken at the longest exposure time without showing any saturation effect was analyzed with the spot diameters set to $160 \mu \mathrm{m}$. Mean fluorescence signal intensity (MFI) of each sample was calculated from referenced, backgroundcorrected mean intensities of the single spots (eight spots per sample) applying a linear fit and interpolating to the mean of the four printed protein concentrations. Blankcorrected MFI signals of the samples were normalized for the relative protein concentration printed on the chip to obtain normalized fluorescence intensity signals (NFI). NFI values were used for all subsequent statistical analyses.

\section{Glucose uptake \& lactate production assay}

Glucose uptake and lactate production assays were performed by using commercially available kits from Cayman chemical (\#600470, \#700510) following manufacturer's protocols. Glucose uptake was measured with a Fluostar Omega fluorescence microplate reader (BMG Labtech, Ortenberg, Germany) and lactate production was quantified with a Molecular Devices Spectra Max 190 microplate reader (Bio-Strategy $\mathrm{P} / \mathrm{L}$, Campbellfield, Vic., Australia).

\section{NpFR2 redox assay}

Intramitochondrial redox status was determined using naphthalimide flavin redox sensor 2 (NpFR2) [48]. Mia PaCa-2 and PGRMC1-HA-expressing stable cells $(1 \times$ $10^{6}$ ) were suspended in $2 \mathrm{~mL}$ complete media and 
seeded in six well plates and cultured for $24 \mathrm{~h}$ at $37^{\circ} \mathrm{C}$ and $5 \% \mathrm{CO}_{2}$. Cells were washed with PBS, trypsinsed, harvested, and resuspended in $1 \mathrm{~mL}$ of fresh media containing $25 \mu \mathrm{M}$ NpFR2 in a $1.5 \mathrm{~mL}$ microcentrifuge tube, followed by incubation for $20 \mathrm{~min}$ at $37^{\circ} \mathrm{C}$. Cells were then centrifuged in a microcentrifuge at $180 \mathrm{x}$ g, the pellet was resuspended once with $1 \mathrm{~mL}$ PBS followed by recentrifugation, and the washed pellet was again resuspended in $1 \mathrm{~mL}$ PBS. Five hundred microliter cell suspension was loaded to a Gallios Flow Cytometer (Beckman Coulter) and fluorescence of $2 \times 10^{4}$ cells was detected using FL1 (green) channel.

\section{Immunofluorescence microscopy}

To detect the expression of exogenous HA tagged PGRMC1 in Fig. 1e, cells were seeded on coverslips on a six well plate. The cells were washed with ice-cold PBS, mildly fixed with $3.7 \%$ formaldehyde for $5 \mathrm{~min}$ at $4{ }^{\circ} \mathrm{C}$. The cells were then permeabilized with ice-cold $100 \%$ methanol for $10 \mathrm{~min}$ at $-20^{\circ} \mathrm{C}$, followed by overnight incubation with anti-HA tag antibody (Sigma, H3663). The cells were washed extensively and incubated with FITC conjugated secondary antibody (Sigma, F8521) in dark for $1 \mathrm{~h}$ at $4{ }^{\circ} \mathrm{C}$. Cells were washed three times with PBS and counterstained with DAPI mounting solution. Images were captured using a Nikon Ti Eclipse Confocal microscope (Nikon Australia Pty Ltd).

\section{Analysis of mitochondrial morphology}

Mitochondria were quantified for cell shape (elongated/ round), mitochondrial content (sum of mitochondrial area/cell), mitochondrial size (average perimeter/cell), and mitochondrial morphology or Formfactor (FF): a measure where higher values correspond to a greater level of filamentous mitochondria and lower values correspond to more highly fragmented mitochondria [52]. FF (calculated as the $\mathrm{P}^{2} / 4 \pi \mathrm{A}$ ) measures mitochondrial morphology based on the perimeter and area of shape. The calculation takes in to account not only changes in length, but also the degree of branching, making at an ideal form of measurement for the quantification of mitochondrial morphology.

To measure FF, $1 \times 10^{5}$ cells were seeded onto Nunc 176740 four well plates with a $22 \times 22 \mathrm{~mm} \# 1.5$ glass coverslip on the bottom. Cells were fixed and permeabilized as above, then incubated with Abcam mouse anti-mitochondrial IgG1 antibody (Abcam ab3298) and then with FITC-conjugated goat anti-mouse secondary antibody (Sigma-Aldrich F4018) and DAPI, followed phalloidin red staining and imaged with 3D-Structured Illumination Microscopy (SIM) on a DeltaVisionOMX Blaze microscope as described [87]. Images were processed using Fiji/ImageJ software [88], and Area and
Perimeter values were extracted to calculate form factor. Cell morphology was scored as either 'round' or 'elongated' by JCC as part of the mitochondrial quantification process.

\section{Holo-tomographic imaging}

Holo-tomographic video imaging was performed on a NanoLive (Switzerland) 3D Cell Explorer fluo (AXT Pty Ltd., Warriewood, NSW) equipped with a NanoLive live cell incubator (AXT Pty Ltd). $1 \times 10^{4}$ cells were seeded into a FluoroDish cell culture dish $35 \mathrm{~mm}, 23 \mathrm{~mm}$ well (World Precision Instruments, FD35) and maintained in phenol red free DMEM medium (Sigma-Aldrich, D1145) supplemented with $10 \%$ fetal bovine calf serum (SigmaAldrich, F9423), $2 \mathrm{mM}$ glutamine (Sigma-Aldrich, G7513) and 1\% penicillin-streptomycin for $48 \mathrm{~h}$. Immediately prior to imaging the medium was removed and replaced with $400 \mu \mathrm{L}$ of the same medium, followed by transfer to the live cell incubator chamber of the 3D Cell Explorer. Cells were incubated at $37^{\circ} \mathrm{C}, 5 \% \mathrm{CO}_{2}$ and $100 \%$ humidity for the duration of the time-lapse. Three dimensional holo-tomographic images were captured every $20 \mathrm{~s}$ for the duration of the time-lapse using the Nanolive STEVE software. For File S7 the center plane of each 96 slice stack was exported after capture using the built in STEVE export wizard as an avi movie file. These files were exported at 5 frames per second (100x actual speed) to visualize cellular dynamics.

\section{Subcutaneous mouse xenograft tumors}

Animal experiments and welfare conformed to the Australian National Health and Medical Research Council guidelines and institutional ethics approval from the Animal Ethics Committee at the Australian National University (E2017/16) and Charles Sturt University Animal Care and Ethics Committee (A17046). NOD/ Shi-SCID/IL-2Rynull (NSG) mice were bred and supplied by the Australian Phenomics Facility at the Australian National University (ANU), an Australian academic center funded by the Australian Government's National Collaborative Research Infrastructure Strategy (NCRS) program, and contributions from ANU. Experiments were performed in the John Curtin School of Medical Research satellite animal facility. Animals were housed in individually ventilated cages with access to food and water ad libitum, enriched with corn cob bedding and a maximum of 5 mice per cage. Animals were injected in four cohorts randomized by weight, and the number of mice per cohort was based on availability. Mice were injected with independently generated cell lines MP, WT1-WT3, DM1-DM3, TM1-TM-3, and Y180F. Cells were expanded in culture for a maximum of 2 weeks before injection. Cells were trypsinized, pelleted, washed with PBS and stored on ice. Cell count was determined 
using a hemocytometer and trypan blue. Two million cells were resuspended in $100 \mu \mathrm{L}$ 50:50 Matrigel:PBS for sub-cutaneous injection into the left flank of female NSG mice (8-12 weeks) via a 27-gauge needle. The total number of mice injected per cell line was based on the replicate coefficient of variation (CV) for solid tumour models evaluating disease burde $n=10 \%, \mathrm{CV}$ being the measure of spread that describes the amount of variability relative to the mean. A t-test-based statistical analysis of simulated differences in mean tumour progression shows that a minimal number of replicates of $n=10$ is necessary to identify a greater than or equal to $20 \%$ change between replicate groups at a pre-determined statistical significance level of $5 \%$. However this was refined in order to reduce animal usage where possible according to the NHMRC Australian code for the care and use of animals for scientific purposes. For cohort 1 four animals each were injected with MP, WT1, DM1, and TM1. For cohort 2 four animals each were injected with WT2, DM2 and TM2, and one animal with MP. For cohort 3 four animals each were injected with WT3, DM3 and TM3, one animal with MP. For cohort 4 five animals were injected with Y180F cells, and one animal with each of MP, WT1, DM1, and TM1. Injection of each cohort commenced mid-morning. Mice were monitored daily and once the tumor was palpable ( 2.5-4 weeks), tumor growth was measured 3 times a week using calipers until at least one tumor in the cohort reached $1 \mathrm{~cm}^{3}$ in volume. Once any animal in any group in the cohort reached the maximum size of tumor all animals were euthanized for tissue recovery by cervical dislocation and tumors were harvested, weighed, photographed, and fixed with formalin.

\section{Statistical analyses}

Unless specified otherwise, statistical analysis was performed using the SPSS package (IBM). Results for WT, DM and TM cells represent equal numbers of three independently derived cell lines for each PGRMC1 condition (e.g. $n=6$ for WT includes $2 x$ WT1, 2xWT2, and 2xWT3). For boxplot data depictions, whiskers represent quartiles 1 and 4 (with maximum and minimum values). Boxes represent quartiles 2 and 3, separated by the median, as generated by SPSS analyze data function. Datasets conforming with normal distribution were analyzed by ANOVA and post-hoc Bonferroni or Tukey HSD test (equal variance) or post-hoc Dunnett's T3 Test (unequal variance). Statistical differences between divergent treatments of different cell lines were calculated using two way ANOVA and post-hoc pairwise comparisons. For non-parametric data sets KruskalWallis or Kolmogorov-Smirnov tests were performed, as indicated in relevant figure legends.

\section{Supplementary information}

Supplementary information accompanies this paper at https://doi.org/10. 1186/s12860-020-00256-3.

Additional file 1: Figure S1. Detailed views of selected pathways identified by WebGestalt analyses. Related to Fig. 3. All panels are adapted from File S6. Heat map colors follow Fig. 3. (A) Principal component (PC) analysis of SWATH-MS proteomics results showing distribution of PC1 and PC2. PC1 corresponded to pathways associated with ribosomes and translation, while PC2 corresponded to pathways associated with mRNA splicing processing (see File S3). (B) Proteins associated with PI3K AKT activity (WebGestalt Database: PC, DB_ID:1648, "Class I PI3K signaling events mediated by AKT") are less abundant in TM cells. (C) F1/ F0 ATPase subunits elevated in WT and TM cells. (D) Abundances of proteins associated with protein folding and microtubule function are altered by PGRMC1 phosphorylation status. Proteins detected in any of the following WebGestalt pathways or functions (1-4) or a manual search (5) are mapped against their expression profiles. 1) cellular component chaperonin-containing T-complex GO:0005832. 2) PC pathway Chaperonin-mediated protein folding DB_ID:710. 3) cellular component microtubule GO:0005874. 4) PC pathway Protein folding DB_ID:712. 5) Description from the list of 243 proteins (File S6) contains keywords "tubulin" or "microtubule" (manual search) (Adapted from File S6). 2-tailed t-test $p$-values for all sample comparisons are available in File S4. (E) Proteins associated with nuclear import/export that are elevated in DM cells. (F) Antigen processing and presentation enzymes are affected by PGRMC1 phosphorylation status. Manual additions to KEGG pathway ID:04612 "Antigen processing and presentation" (no yellow shading: from File S6 and File S5) are indicated with yellow highlighting. Figure S2. Highest and lowest differentially abundant proteins. Panels show the six most $(+)$ and least $(-)$ abundant proteins for each cell type that were significantly differentially abundant between cell types. Related to Fig. 3. Identical colored symbols depict the same protein in different cell types, where circles represent high abundance and triangles represent low abundance. E.g. Mitochondrial import receptor subunit TOM40 (O96008), CDP-diacylglycerol-inositol 3-phosphatidyltransferase (CDIPT, 014735) (phosphatidylinositol synthesis) and transcriptional coactivator PSIP1 (O75475) are more abundant in WT and TM. Aldehyde dehydrogenase 1 A3 (P47895), APOC3 (P02656) and APOA1 (P02647) are less abundant in DM and TM, whereas the receptor tyrosine kinase ephrin type-A receptor 2 (EPHA2, P29317) is among the lowest abundance differential proteins in WT and TM. Protein abundances (measured ion intensities) for all proteins are available in File S2. Figure S3. Proteins associated with predicted Estrogen Receptor Related 1 (ERR1) transcription factor activity are more abundant in WT and TM cells. Related to Fig. 3 and File S6. Data are available via ProteomeXchange with identifier PXD014789. (A) Proteins quantified by SWATH-MS and predicted by WebGestalt Transcription Factor target enrichment analysis (WebGestalt Database: Transcription Target, Name: hsa_TGACCTY_V\$ERR1_Q2, ID:DB_ID:2414) to be dependent upon ERR1 transcription (Adapted from File S6). Heat map colors follow Fig. 3. (B) Western blot of shRNA attenuation of ERR1 (top panel) in WT cells, compared to scramble shRNA control. Lower panel: beta actin loading control. (C) ERR1 attenuation by shRNA induces morphological changes to WT cells. (D) Ratio of rounded to other cells as scored for replicate images from each of the cell lines from B. $p<0.0005,1$ tailed t-test. (E) SWATH MS quantification of proteins significantly differentially abundant between cells expressing scramble shRNA or anti-ERR1 shRNA (according to the selection criteria of File S4). Fifty-seven proteins became more abundant after shRNA depletion of ERR1, and 19 proteins became less abundant. In this panel green depicts lower abundance and red depicts higher abundance. Brown depicts similar abundance. (F) Proteins present in (E) which are also present in the 243 protein list of File S6. Heat map colors follow Fig. 3. The left panel shows expression in the original result of File S6. The right panel shows expression in the presence of scramble shRNA or anti-ESSR1 shRNA. All proteins from Fig. S3A except Q9BPW8 were detected in the shRNA experiment. Double headed arrows indicate proteins which differ in expression tendency between WT (left) and WTscramble shRNA cells (right). This may be caused by the puromycin selection of both sh-scr and shERR1 cells but not the parental WT cells, however this requires further investigation. Proteins with Uniprot ID 
highlighted by asterisk (bold red) are those both originally predicted by WebGestalt to be associated with ERR1 transcription factor (A), and which exhibited significantly altered abundance after shRNA attenuation of ERR1 protein. Figure S4. The DM migratory phenotype is dependent upon Vinculin. Related to Fig. 3. (A) Proteins associated with actin-myosin contraction (WebGestalt Database: PC, DB_ID:144, "Smooth Muscle Contraction") are more abundant in DM cells. Heat map colors follow Fig. 3. (B) Western blot of Vinculin (VCL) and actin levels in cells expressing scramble control (shScr) or anti Vinclulin (shVNC) shRNA. (C) Scratch assays as indicated were performed following the methods of Fig. 1e-f. (D) Boxplot showing results of 12 replicates of (C). ANOVA gave $F=78.7, p<$ 0.00001. The table shows post-hoc Dunnet's T3 $p$-values. Figure S5. PGRMC1 phosphorylation status affects mitochondrial function. Related to Fig. 5. (A) Representative flow cytometry results of cells labeled with NpFR2. The percentage of the cell population to the right of the dashed reference line (interval labeled " $\mathrm{B}$ ", marked by the dotted line) is quantified for each measurement. White arrows indicate more oxidized NpFR2 fluorescence in WT and TM cells. (B) Boxplots of the percentage of cells exhibiting $>10$ fluorescent intensity units to the right of the reference line in (A). $n=6$ for each cell type, being 6 replicates of MP cells, or duplicate measurements of each of 3 independent lines $1-3(n=3 \times 2=6)$ for WT, DM and TM cells. White arrows indicate the same differences as in (A). There was significant difference between the means (Kruskal-Wallis Test $p<0.0001$ ). Independent sample median tests revealed that all medians were significantly different from one another $(p<0.001)$. (C) Representative flow cytometry results of cells labeled with MitoTracker. The respective panels depict fluorescence intensity ( $x$ axis) plotted against either side scatter (left/black plots) or cell number (right/red plots), with or without the addition of MitoTracker as indicated. MitoTracker affinity for mitochondria is increased with higher mitochondrial membrane potential $(\Delta \psi \mathrm{m})$, such that respective left MitoTracker-treated populations/peaks represent low $\Delta \psi \mathrm{m}$ populations, and respective right MitoTracker-treated populations/peaks represent high $\psi \mathrm{m}$ populations. Vertical dotted lines for Mitotracker-treated cells depict the MFI for MP cell low and high $\Delta \psi \mathrm{m}$ populations. The black arrow for DM cells with Mitotracker highlights reduced MFI of both the low and high $\Delta \psi \mathrm{m}$ DM cell populations. The white arrow highlights the reduced proportion of DM cells in the low $\Delta \psi \mathrm{m}$ peak. The same arrows are depicted for replicates in $(D)$ and $(E)$ respectively. (D) Median Fluorescent Intensity (MFI) for each of the cell populations observed from (C). $n=6$ measurements per cell type, as per (B). Error bars depict standard deviation. The low and high $\Delta \psi \mathrm{m}$ populations correspond to the respective populations from (C). For low $\Delta \psi m$ cells the means were significantly different between cell types (ANOVA, post-hoc Dunnet's T3, $p<0.003)$. For high $\Delta \psi \mathrm{m}$ cells WT vs. TM $(p<0.05)$ and other comparisons $(p<0.004)$ were significantly different (KruskallWallis). Tables $D(L)$ and $D(H)$ show pairwise comparison $p$-values for low $\Delta \psi m(F(L))$ and high $\Delta \psi m(F(H))$ cells. (E) The percentage of cells in each of the low and high $\Delta \psi m$ populations from (C) and (D), from the same data. Standard deviation error bars for the respective high $\Delta \psi \mathrm{m}$ (upper error bar) and low $\Delta \psi \mathrm{m}$ (lower error bar) cell populations are given for each cell type. Color-coding and all other terminology follows (C). For low $\Delta \psi \mathrm{m}$ cells, Shapiro-Wilk's test showed normal distributions, and Levene's test revealed non-homogenous variance $(p=0.04)$. Table $\mathrm{E}$ shows $p$-values for ANOVA/post-hoc Dunnet's T3 test pairwise comparisons. $(F, G)$ Area under curve (AUC) plots for basal and FCCP curves from (Fig. 5c) showing one way ANOVA/post-hoc Bonferroni $p$-values between samples in the respective indicated regions.

Additional file 2: File S1. A zip archive containing time lapse mp4 movies of migrating cells in scratch assays. Related to Fig. 1. Images were taken at 10 min intervals over $36 \mathrm{~h}$ and are replayed over $65 \mathrm{~s}$ at 9 frames per second (2000x real time). The presented 32.4 MB MP4 files were generated from the original $666 \mathrm{MB}$ (6000x real time) .avi files (length 21 s, frame width $\mathrm{x}$ height $1024 \times 1024$, Data rate/bit rate $287,462 \mathrm{kbps}$, frame rate $100 \mathrm{fps}$ ) by processing in Adobe Premiere Pro 2017 using the following settings: Preset "custom"; Width: 1024; Height 1024; Aspect Square Pixels (1.0); Field Order: progressive; Profile: high; Target Bitrate [Mbps] 4.08; Maximum Bitrate [Mbps] 4.39; 9 fps; No Audio; Output as standard .mp4; Time Interpolation: Frame Sampling; Stream Compatibility: Standard; Variable bit rate, single pass; Number of frames 00:01:04:09. The zip archive contains 4 files with filenames representing cell type and date of measurement (yyyymmdd). (A) A MP_20170807.mp4. (B) B_WT_20170809.mp4. (C) C_DM_20170815.mp4. (D) D_TM_20170817.mp4.

Additional file 3: File S2. An Excel file showing experimental design, normalized ion intensities for 1330 proteins identified by SWATH-MS proteomics, and six pairwise comparisons between the 4 sample types [1) $M P \vee$. WT, 2) MP v. DM, 3) MP v. TM, 4) WT v. DM, 5) WT v. TM, and 6) DM v. TM]. Related to Fig. 3. The first tab contains a detailed descriptive legend. Data are available via ProteomeXchange with identifier PXD014716.

Additional file 4: File S3. Principal component analysis results for pathways associated with SWATH-MS proteomics results.

Additional file 5: File S4. An excel file containing proteomics results for 243 proteins which fulfil stringency criteria of t-test $p$-value of less than 0.05 , and a fold change greater than 1.5 by both the protein and peptide approaches from File S2. Related to Fig. 3. Column B shows "red" (more abundant in comparative sample 1) and "blue" (less abundant in sample 1) significantly differential proteins for each pair wise comparison which were later used for "red" and "blue" WebGestalt pathways enrichment analysis (File S5). Comparisons follow File S2.

Additional file 6: File S5. WebGestalt pathway mapping excel results file for red and blue proteins from File S4. Related to Fig. 3. (A) WebGestalt Features (GO, KEGG Pathways, Wikipathways, Pathway Commons, Transcription Factors) significant at the adjP $\leq 0.001$ level between any 2 comparisons. (B) Features from $A$, viewed at the adjP< 0.05 level for each red and blue comparison, and showing adjusted $p$ values (adjP) for each comparison where adjP $<0.05$ (or adjP $<0.1$ for two comparisons as indicated by paler coloring). Blue means that proteins associated with a given the feature were less abundant in that cell line, with red indicating higher abundance. Because separate WebGestalt analyses were performed for red and blue lists of proteins from File S4, some features were significant for both red and blue. In that case the color and adjp for the most significant analysis is given, with the other cell being colored black.

Additional file 7: File S6. An excel file with heat map protein IDs and pathways for red vs. blue pathways adjP $<0.001$. Related to Fig. 3 . This file is derived from the results of File S5, and is the source file for Fig. 3. Proteins suggested by clustering by inferred models of evolution (CLIME) analysis to co-evolve with PGRMC1 with log likelihood ratio greater than 12 [21] are present in the list, marked yellow for mitochondrial localization (WebGestalt GO:0005739) or green for cytoplasmic (P00387)

Additional file 8: File S7. A zip archive containing time lapse Holotomographic video.avi files of cells. These images are based upon differences in refractive index [53], and are provided for the dynamic visualization of mitochondria. Prominent visible features include small white lipid droplets and cholesterol-rich mitochondria [21], as well as nuclear membrane and nucleoli. The previously described MIA PaCa-2 cell bleb-like protrusions [34] are apparent as highly dynamic rearrangements of the cytoplasmic membrane, which may contribute to intercellular communication. (A) MP cells. (B) WT cells. (C) DM cells. (D) TM cells.

\section{Abbreviations}

adjP: Benjamini-Hochberg adjusted $p$-value; avFF: average mitochondrial form factor; CK2: Casein kinase 2; DM: Hemagglutinin-tagged PGRMC1 S57A/ S181 double mutant; EMT: Epithelial-mesenchymal transition; ERR1: Estrogen receptor related 1; FF: Mitochondrial form factor; hPSCs: human pluripotent stem cells; IDA: Information dependent acquisition; LDLR: Low density lipoprotein receptor; MAT: Mesenchymal-amoeboid transition; MP: MIA PaCa2 pancreatic cancer; MS/MS: Tandem mass spectrometry; MTT: 3-(4,5dimethylthiazolyl-2)-2,5-diphenyltetrazolium bromide; NpFR2: Naphthalimideflavin redox sensor 2; P4: Progesterone; PAQR7: Progestin and adipoQ receptor 7; PGRMC1: Progesterone Receptor Membrane Component 1; PGRMC2: Progesterone Receptor Membrane Component 2; ROCK: Rho kinase; ROCKI: Rho kinase inhibitor; RPPA: Reverse Phase Protein Array; S2R: Sigma-2 receptor; SH2: Src homology 2; SH3: Src homology 3; SWATHMS: Sequential Window Acquisition of all Theoretical Mass Spectrometry; TM: Hemagglutinin-tagged PGRMC1 S57A/Y180F/S181 triple mutant; TRiC: Tcomplex protein-1 ring complex; WT: Hemagglutinin-tagged PGRMC1 wild type; $\Delta \psi \mathrm{m}$ : Mitochondrial membrane potential 


\section{Acknowledgements}

The publication hiatus of more than a decade on this project has been caused by the Australian competitive grants system failing to support a single funding application from M.A.C. after his relocation with the PGRMC1 project from Germany to a regional Australian university. We thank Padraig Strappe for the gift of lentiviral helper packaging plasmids and HEK293 cells. MIA PaCa-2 (MP) pancreatic cancer cells were obtained from Dr. Patsy Soon, Kolling Institute of Medical Research, Sydney. We thank Jean Yang for assistance in establishing the project.

\section{Authors' contributions}

All authors have read and approved the manuscript. Conceptualization, M.A.C.; Methodology, M.A.C, P.P.A, A.V.O., M.P., E.J.N, S.J.K., K.M.H, R.D.H., and M.P.M; Software, D.P. (proteomics); Formal Analysis, P.P.A., D.P., M.J., E.P. M.A.C., and M.J.; Investigation, B.M.T., P.P.A., S.L.T., A.V.O., A.K., I.S., T.Z., C.P.C., D.P., L.T., M.P., P.P., and J.C.C.; Resources, M.P.M., M.P., E.J.N., H.N., and T.F.; Writing - Original Draft, M.A.C.; Writing - Review \& Editing, M.P.M., M.A.C. P.P.A., E.M.G., C.P.C., B.M.T., M.P., E.M.G, and T.L.R.; Visualization, M.A.C.; Supervision, M.A.C, J.A.J., E.M.G., E.J.N., T.L.R, and M.P.M.; Project Administration, M.A.C.; Funding Acquisition, M.A.C., J.A.J., B.M.T., E.M.G., M.P.M., T.L.R., and E.J.N.

\section{Funding}

This work has received no direct Australian competitive grant support since M.A.C.'s relocation to the country in 2008. The present results have been compiled largely due to the generosity of collaborating authors, and by the $\mathrm{PhD}$ stipends of B.M.T. and P.P.A. Research was primarily supported by Charles Sturt University internal funds to M.A.C and J.A.J, and by collaborating labs. Open access publication fees were jointly supported by CSU's Faculty of Science, School of Biomedical Sciences, and Research Office. B.M.T. was supported by a PhD scholarship from the Ministry of Higher Education and Research, through the University of Wasit, Iraq. A.K. acknowledges the University of Sydney for a World Scholars Scholarship. E.M.G. acknowledges partial support of Australian Research Council award CE140100003. E.J.N. acknowledges the support of the Australian Research Council (DE120102687) and the Ramaciotti Foundation (ES2012/0051). T.L.R is supported by a Cancer Institute New South Wales Future Research Leader Fellowship. M.P. is supported by a NHMRC RD Wright Biomedical Career Development Fellowship and the Cancer Institute NSW Career Development Fellowship. The funding bodies played no role in the design of the study and collection, analysis, and interpretation of data and in writing the manuscript.

\section{Availability of data and materials}

The mass spectrometry proteomics data have been deposited to the ProteomeXchange Consortium via the PRIDE partner repository (http://www. ebi.ac.uk/pride) with the dataset identifiers PXD014716 (Fig. 3) and PXD014789 (Fig. S3). Further data are provided in supporting information files available from the journal web page.

\section{Ethics approval and consent to participate}

Mouse experiments were approved by The Australian National University Animal Experimentation Ethics Committee ethics protocol ANU A2017/16, and by Charles Sturt University Animal Care and Ethics Committee ethics protocol CSU A17046. ANU ethics approval and the provision agreement with the Australian Phenomics Facility at the Australian National University (ANU) (the provider of animals), included permission to use the animals in this study.

\section{Consent for publication}

Not applicable.

\section{Competing interests}

M.A.C. is scientific advisor to and minor shareholder of Cognition Therapeutics, a company developing sigma-2 receptor ligands against Alzheimer's disease. This work was performed independently of and without input from the company. The authors declare that they have no other competing interests.

\section{Author details}

${ }^{1}$ School of Biomedical Sciences, Charles Sturt University, Wagga Wagga, NSW 2650, Australia. ${ }^{2}$ Department of Biology, College of Science, University of Wasit, Wasit 00964, Iraq. ${ }^{3}$ Present address: Faculty of Pharmaceutical Sciences, The University of British Columbia, Vancouver V6T 1Z4, Canada. ${ }^{4}$ School of Chemistry, University of Sydney, Sydney, NSW 2006, Australia. ${ }^{5}$ Present address: School of Medical Sciences, University of Sydney, Sydney, NSW 2006, Australia. ${ }^{6}$ Life Sciences and Health, Faculty of Science, Charles Sturt University, Wagga Wagga, NSW 2650, Australia. ${ }^{7}$ The Kinghorn Cancer Centre, Cancer Division, Garvan Institute of Medical Research, 384 Victoria St, Darlinghurst, Sydney, NSW 2010, Australia. ${ }^{8}$ St Vincent's Clinical School, Faculty of Medicine, University of NSW, Darlinghurst 2010, NSW, Australia. ${ }^{9}$ Department of Biochemistry and Molecular Biology, University of Melbourne, Parkville, Victoria 3010, Australia. ${ }^{10}$ ACRF Department of Cancer Biology and Therapeutics, The John Curtin School of Medical Research, The Australian National University, ACT, Canberra 2601, Australia. ${ }^{11}$ Australian Proteome Analysis Facility, Macquarie University, Sydney, NSW 2109, Australia. ${ }^{12}$ Department of Gynecology and Obstetrics, University Women's Hospital of Dusseldorf, 40225 Dusseldorf, Germany. ${ }^{13}$ NMI TT Pharmaservices, Protein Profiling, 72770 Reutlingen, Germany. ${ }^{14}$ Particles-Biology Interactions Laboratory, Department of Materials Meet Life, Swiss Federal Laboratories for Materials Science \& Technology (Empa), Lerchenfeldstrasse 5, CH-9014 St Gallen, Switzerland. ${ }^{15}$ The ithree institute, University of Technology Sydney, Ultimo, NSW 2007, Australia. ${ }^{16}$ Present address: GE Healthcare Life Sciences, Issaquah, WA 98027, USA. ${ }^{17}$ Department of Mathematics and Statistics, La Trobe University, Melbourne, VIC 3086, Australia. ${ }^{18}$ Ingham Institute for Applied Medical Research, Liverpool, NSW 2170, Australia. ${ }^{19}$ School of Medicine, Western Sydney University, Locked Bag 1797, Penrith, NSW 2751, Australia. ${ }^{20}$ South Western Sydney Clinical School, Faculty of Medicine, The University of New South Wales, Liverpool, NSW 2170, Australia. ${ }^{21}$ School of Medicine and University of Queensland Centre for Clinical Research, Herston, QLD 4006, Australia. ${ }^{22}$ AXT Pty Ltd, Warriewood (Sydney), NSW 2102, Australia. ${ }^{23}$ Division of Research, Peter MacCallum Cancer Centre, Melbourne, Victoria 3000, Australia. ${ }^{24}$ Sir Peter MacCallum Department of Oncology, University of Melbourne, Parkville, Victoria 3010, Australia. ${ }^{25}$ Department of Biochemistry and Molecular Biology, Monash University, Clayton, Victoria 3168 , Australia. ${ }^{26}$ School of Mathematics and Statistics, University of Sydney, Sydney, NSW 2006, Australia. ${ }^{27}$ Present address: The Kolling Institute, The University of Sydney, St Leonards (Sydney), NSW 2064, Australia. ${ }^{28}$ ARC Centre of Excellence for Nanoscale BioPhotonics, Macquarie University, Sydney, NSW 2109, Australia. ${ }^{29}$ Present address: The Graduate School of Biomedical Engineering, University of New South Wales, Sydney, Kensington, NSW 2052, Australia. ${ }^{30}$ Graham Centre for Agricultural Innovation, Charles Sturt University, Boorooma Street, Wagga Wagga, NSW 2678, Australia.

${ }^{31}$ School of Agricultural and Wine Sciences, Charles Sturt University, Boorooma Street, Wagga Wagga, NSW 2678, Australia.

Received: 16 January 2020 Accepted: 4 March 2020 Published online: 03 April 2020

\section{References}

1. Riad A, Zeng C, Weng CC, Winters H, Xu K, Makvandi M, Metz T, Carlin S, Mach $\mathrm{RH}$. Sigma-2 receptor/TMEM97 and PGRMC-1 increase the rate of internalization of $L D L$ by $L D L$ receptor through the formation of a ternary complex. Sci Rep. 2018;8(1):16845.

2. Cahill MA, Jazayeri JA, Catalano SM, Toyokuni S, Kovacevic Z, Richardson DR. The emerging role of progesterone receptor membrane component 1 (PGRMC1) in cancer biology. Biochim Biophys Acta. 2016;1866(2):339-49.

3. Ryu CS, Klein K, Zanger UM. Membrane associated progesterone receptors: promiscuous proteins with pleiotropic functions - focus on interactions with cytochromes P450. Front Pharmacol. 2017;8:159.

4. Peluso JJ, Griffin D, Liu X, Horne M. Progesterone receptor membrane component-1 (PGRMC1) and PGRMC-2 interact to suppress entry into the cell cycle in spontaneously immortalized rat granulosa cells. Biol Reprod. 2014;91(5):104.

5. Sueldo C, Liu X, Peluso JJ. Progestin and AdipoQ receptor 7, progesterone membrane receptor component 1 (PGRMC1), and PGRMC2 and their role in regulating Progesterone's ability to suppress human Granulosa/luteal cells from entering into the cell cycle. Biol Reprod. 2015;93(3):63.

6. Luciano AM, Lodde V, Franciosi F, Ceciliani F, Peluso JJ. Progesterone receptor membrane component 1 expression and putative function in 
bovine oocyte maturation, fertilization, and early embryonic development. Reproduction (Cambridge, England). 2010;140(5):663-72.

7. Luciano AM, Peluso JJ. PGRMC1 and the faithful progression through mitosis and meiosis. Cell cycle (Georgetown, Tex). 2016;15(17):2239-40.

8. Terzaghi L, Luciano AM, Dall'Acqua PC, Modina SC, Peluso JJ, Lodde V. PGRMC1 localization and putative function in the nucleolus of bovine granulosa cells and oocytes. Darlinghurst: Reproduction (Cambridge, England). 2018;155(3):273-82.

9. Terzaghi L, Tessaro I, Raucci F, Merico V, Mazzini G, Garagna S, Zuccotti M, Franciosi F, Lodde V. PGRMC1 participates in late events of bovine granulosa cells mitosis and oocyte meiosis. Cell cycle (Georgetown, Tex). 2016;15(15):2019-32.

10. Rohe HJ, Ahmed IS, Twist KE, Craven RJ. PGRMC1 (progesterone receptor membrane component 1): a targetable protein with multiple functions in steroid signaling, P450 activation and drug binding. Pharmacol Ther. 2009; 121(1):14-9.

11. Ahmed IS, Rohe HJ, Twist KE, Mattingly MN, Craven RJ. Progesterone receptor membrane component 1 (Pgrmc1): a heme-1 domain protein that promotes tumorigenesis and is inhibited by a small molecule. J Pharmacol Exp Ther. 2010;333(2):564-73.

12. Losel RM, Besong D, Peluso JJ, Wehling M. Progesterone receptor membrane component 1--many tasks for a versatile protein. Steroids. 2008; 73(9-10):929-34.

13. Ruan X, Zhang Y, Mueck AO, Willibald M, Seeger H, Fehm T, Brucker S, Neubauer $\mathrm{H}$. Increased expression of progesterone receptor membrane component 1 is associated with aggressive phenotype and poor prognosis in ER-positive and negative breast cancer. Menopause (New York, NY). 2017; 24(2):203-9.

14. Willibald M, Wurster I, Meisner C, Vogel U, Seeger H, Mueck AO, Fehm T, Neubauer H. High Level of Progesteron Receptor Membrane Component 1 (PGRMC 1) in Tissue of Breast Cancer Patients is Associated with Worse Response to Anthracycline-Based Neoadjuvant Therapy. Horm Metab Res. 2017;49(8):595-603.

15. Shih CC, Chou HC, Chen YJ, Kuo WH, Chan CH, Lin YC, Liao EC, Chang SJ, Chan HL. Role of PGRMC1 in cell physiology of cervical cancer. Life Sci. 2019;231(19):116541.

16. Cahill MA. Progesterone receptor membrane component 1: an integrative review. J Steroid Biochem Mol Biol. 2007:105(1-5):16-36.

17. Peluso JJ, Pappalardo A, Losel R, Wehling M. Progesterone membrane receptor component 1 expression in the immature rat ovary and its role in mediating progesterone's antiapoptotic action. Endocrinology. 2006;147(6): 3133-40.

18. Franchin C, Borgo C, Cesaro L, Zaramella S, Vilardell J, Salvi M, Arrigoni G, Pinna LA. Re-evaluation of protein kinase CK2 pleiotropy: new insights provided by a phosphoproteomics analysis of CK2 knockout cells. Cell Mol Life Sci. 2018;75(11):2011-26.

19. Cahill MA, Jazayeri JA, Kovacevic Z, Richardson DR. PGRMC1 regulation by phosphorylation: potential new insights in controlling biological activity. Oncotarget. 2016;7(32):50822-7.

20. Cahill MA. The evolutionary appearance of signaling motifs in PGRMC1. Biosci Trends. 2017;11(2):179-92.

21. Cahill MA, Medlock AE. Thoughts on interactions between PGRMC1 and diverse attested and potential hydrophobic ligands. J Steroid Biochem Mol Biol. 2017;171:11-33.

22. Hehenberger E, Eitel M, Fortunato SAV, Miller DJ, Keeling PJ, Cahill MA. Early eukaryotic origins and metazoan elaboration of MAPR family proteins. bioRxiv. 2019: bioRxiv preprint (not peer-reviewed). https://doi.org/10.1101/737684.

23. Etchevers HC, Dupin E, Le Douarin NM. The diverse neural crest: from embryology to human pathology. Development (Cambridge, England). 2019;146(5):dev169821.

24. Neubauer H, Clare SE, Wozny W, Schwall GP, Poznanovic S, Stegmann W, Vogel U, Sotlar K, Wallwiener D, Kurek R, et al. Breast cancer proteomics reveals correlation between estrogen receptor status and differential phosphorylation of PGRMC1. Breast Cancer Res. 2008;10(5):R85.

25. Sabbir MG. Progesterone induced Warburg effect in HEK293 cells is associated with post-translational modifications and proteasomal degradation of progesterone receptor membrane component 1. J Steroid Biochem Mol Biol. 2019;191:105376.

26. Gras F, Brunmair B, Quarre L, Szocs Z, Waldhausl W, Furnsinn C. Progesterone impairs cell respiration and suppresses a compensatory increase in glucose transport in isolated rat skeletal muscle: a non-genomic mechanism contributing to metabolic adaptation to late pregnancy? Diabetologia. 2007;50(12):2544-52.

27. Hampton KK, Anderson K, Frazier H, Thibault O, Craven RJ. Insulin receptor plasma membrane levels increased by the progesterone receptor membrane component 1. Mol Pharmacol. 2018;94(1):665-73.

28. Wu H, Wu ZG, Shi WJ, Gao H, Wu HH, Bian F, Jia PP, Hou YN. Effects of progesterone on glucose uptake in neurons of Alzheimer's disease animals and cell models. Life Sci. 2019;238:116979.

29. Yunis AA, Arimura GK, Russin DJ. Human pancreatic carcinoma (MIA PaCa-2) in continuous culture: sensitivity to asparaginase. Int J Cancer J Int Du Cancer. 1977;19(1):128-35.

30. Han EK, McGonigal T, Butler C, Giranda VL, Luo Y. Characterization of Akt overexpression in MiaPaCa-2 cells: prohibitin is an Akt substrate both in vitro and in cells. Anticancer Res. 2008;28(2A):957-63.

31. Duong HQ, Hong YB, Kim JS, Lee HS, Yi YW, Kim YJ, Wang A, Zhao W, Cho $\mathrm{CH}$, Seong YS, et al. Inhibition of checkpoint kinase 2 (CHK2) enhances sensitivity of pancreatic adenocarcinoma cells to gemcitabine. J Cell Mol Med. 2013;17(10):1261-70.

32. Iwagami Y, Eguchi H, Nagano H, Akita H, Hama N, Wada H, Kawamoto K, Kobayashi S, Tomokuni A, Tomimaru Y, et al. miR-320c regulates gemcitabine-resistance in pancreatic cancer via SMARCC1. Br J Cancer. 2013; 109(2):502-11.

33. Gosnell ME, Anwer AG, Mahbub SB, Menon Perinchery S, Inglis DW, Adhikary PP, Jazayeri JA, Cahill MA, Saad S, Pollock CA, et al. Quantitative non-invasive cell characterisation and discrimination based on multispectral autofluorescence features. Sci Rep. 2016;6:23453.

34. Gradiz R, Silva HC, Carvalho L, Botelho MF, Mota-Pinto A. MIA PaCa-2 and PANC-1 - pancreas ductal adenocarcinoma cell lines with neuroendocrine differentiation and somatostatin receptors. Sci Rep. 2016;6:21648.

35. Fujita M, Otsuka Y, Yamada S, Iwakawa M, Imai T. X-ray irradiation and rhokinase inhibitor additively induce invasiveness of the cells of the pancreatic cancer line, MIAPaCa-2, which exhibits mesenchymal and amoeboid motility. Cancer Sci. 2011;102(4):792-8.

36. Thejer BM, Adhikary PP, Teakel SL, Fang J, Weston PA, Gurusinghe S, Anwer AG, Gosnell M, Jazayeri JA, Ludescher M, et al. PGRMC1 effects on metabolism, genomic mutation and CpG methylation imply crucial roles in animal biology and disease. ResearchSquare preprint (not peer-reviewed); 2020. https://dx.doi.org/10.21203/rs.2.20008/v2.

37. Suchanek M, Radzikowska A, Thiele C. Photo-leucine and photo-methionine allow identification of protein-protein interactions in living cells. Nat Methods. 2005;2(4):261-7.

38. Matsuoka T, Yashiro M. Rho/ROCK signaling in motility and metastasis of gastric cancer. World J Gastroenterol. 2014;20(38):13756-66.

39. Cha D, O'Brien P, O'Toole EA, Woodley DT, Hudson LG. Enhanced modulation of keratinocyte motility by transforming growth factor-alpha (TGF-alpha) relative to epidermal growth factor (EGF). J Invest Dermatol. 1996:106(4):590-7.

40. Bordeleau ME, Aucagne R, Chagraoui J, Girard S, Mayotte N, Bonneil E, Thibault P, Pabst C, Bergeron A, Barabe F, et al. UBAP2L is a novel BMI1interacting protein essential for hematopoietic stem cell activity. Blood. 2014;124(15):2362-9.

41. Harada H, Becknell B, Wilm M, Mann M, Huang L, Taylor SS, Scott JD, Korsmeyer SJ. Phosphorylation and inactivation of BAD by mitochondriaanchored protein kinase a. Mol Cell. 1999;3(4):413-22.

42. Hayakawa J, Ohmichi M, Kurachi H, Kanda Y, Hisamoto K, Nishio Y, Adachi K, Tasaka K, Kanzaki T, Murata Y. Inhibition of BAD phosphorylation either at serine 112 via extracellular signal-regulated protein kinase cascade or at serine 136 via Akt cascade sensitizes human ovarian cancer cells to cisplatin. Cancer Res. 2000;60(21):5988-94.

43. Cross DA, Alessi DR, Cohen P, Andjelkovich M, Hemmings BA. Inhibition of glycogen synthase kinase- 3 by insulin mediated by protein kinase B. Nature. 1995:378(6559):785-9.

44. Antonietti $P$, Linder $B$, Hehlgans S, Mildenberger IC, Burger MC, Fulda S, Steinbach JP, Gessler F, Rodel F, Mittelbronn M, et al. Interference with the HSF1/HSP70/BAG3 pathway primes Glioma cells to matrix detachment and $\mathrm{BH} 3$ mimetic-induced apoptosis. Mol Cancer Ther. 2017;16(1):156-68

45. Joshi B, Strugnell SS, Goetz JG, Kojic LD, Cox ME, Griffith OL, Chan SK, Jones SJ, Leung SP, Masoudi H, et al. Phosphorylated caveolin-1 regulates rho/ ROCK-dependent focal adhesion dynamics and tumor cell migration and invasion. Cancer Res. 2008;68(20):8210-20. 
46. Le Clainche C, Dwivedi SP, Didry D, Carlier MF. Vinculin is a dually regulated actin filament barbed end-capping and side-binding protein. J Biol Chem. 2010;285(30):23420-32.

47. Pal I, Rajesh Y, Banik P, Dey G, Dey KK, Bharti R, Naskar D, Chakraborty S, Ghosh SK, Das SK, et al. Prevention of epithelial to mesenchymal transition in colorectal carcinoma by regulation of the E-cadherin-beta-cateninvinculin axis. Cancer Lett. 2019;452:254-63.

48. Kaur A, Brigden KW, Cashman TF, Fraser ST, New EJ. Mitochondrially targeted redox probe reveals the variations in oxidative capacity of the haematopoietic cells. Org Biomol Chem. 2015;13(24):6686-9.

49. Perry SW, Norman JP, Barbieri J, Brown EB, Gelbard HA. Mitochondrial membrane potential probes and the proton gradient: a practical usage guide. BioTechniques. 2011;50(2):98-115.

50. Turrens JF. Mitochondrial formation of reactive oxygen species. J Physiol. 2003;552(Pt 2):335-44.

51. Gosnell ME, Anwer AG, Cassano JC, Sue CM, Goldys EM. Functional hyperspectral imaging captures subtle details of cell metabolism in olfactory neurosphere cells, disease-specific models of neurodegenerative disorders. Biochim Biophys Acta. 2016;1863(1):56-63.

52. Koopman WJ, Visch HJ, Smeitink JA, Willems PH. Simultaneous quantitative measurement and automated analysis of mitochondrial morphology, mass, potential, and motility in living human skin fibroblasts. Cytometry A. 2006;69(1):1-12.

53. Ali A, Abouleila Y, Amer S, Furushima R, Emara S, Equis S, Cotte $Y$, Masujima T. Quantitative live single-cell mass spectrometry with spatial evaluation by three-dimensional holographic and tomographic laser microscopy. Anal Sci. 2016;32(2):125-7.

54. Anesti V, Scorrano L. The relationship between mitochondrial shape and function and the cytoskeleton. Biochim Biophys Acta. 2006;1757(5-6):692-9.

55. Sahai E, Marshall CJ. Differing modes of tumour cell invasion have distinct requirements for rho/ROCK signalling and extracellular proteolysis. Nat Cell Biol. 2003;5(8):711-9.

56. Seol HJ, Chang JH, Yamamoto J, Romagnuolo R, Suh Y, Weeks A, Agnihotri S, Smith CA, Rutka JT. Overexpression of CD99 increases the migration and invasiveness of human malignant Glioma cells. Genes Cancer. 2012;3(9-10):535-49.

57. Taddei ML, Giannoni E, Morandi A, Ippolito L, Ramazzotti M, Callari M, Gandellini P, Chiarugi P. Mesenchymal to amoeboid transition is associated with stem-like features of melanoma cells. Cell Commun Signal. 2014;12:24.

58. Friedl P. Prespecification and plasticity: shifting mechanisms of cell migration. Curr Opin Cell Biol. 2004;16(1):14-23.

59. Parri M, Taddei ML, Bianchini F, Calorini L, Chiarugi P. EphA2 reexpression prompts invasion of melanoma cells shifting from mesenchymal to amoeboid-like motility style. Cancer Res. 2009;69(5):2072-81.

60. Friedl P, Wolf K. Plasticity of cell migration: a multiscale tuning model. J Cell Biol. 2010;188(1):11-9.

61. Wai T, Langer T. Mitochondrial dynamics and metabolic regulation. Trends Endocrinol Metab. 2016;27(2):105-17.

62. Piel RB 3rd, Shiferaw MT, Vashisht AA, Marcero JR, Praissman JL, Phillips JD, Wohlschlegel JA, Medlock AE. A novel role for progesterone receptor membrane component 1 (PGRMC1): a partner and regulator of Ferrochelatase. Biochemistry. 2016;55(37):5204-17.

63. Kim HJ, Choi WJ, Lee $\mathrm{CH}$. Phosphorylation and reorganization of keratin networks: implications for carcinogenesis and epithelial Mesenchymal transition. Biomol Ther. 2015;23(4):301-12.

64. Teakel SL, Ludescher M, Thejer BM, Poschmann G, Forwood JK, Neubauer H, Cahill MA. Protein complexes including PGRMC1 and actin-associated proteins are disrupted by AG-205. Biochem Biophys Res Commun. 2020; 524(1):64-69.

65. Roh SH, Kasembeli M, Bakthavatsalam D, Chiu W, Tweardy DJ. Contribution of the type II Chaperonin, TRiC/CCT, to Oncogenesis. Int J Mol Sci. 2015;16(11):26706-20.

66. Boudiaf-Benmammar C, Cresteil T, Melki R. The cytosolic chaperonin CCT/ TRiC and cancer cell proliferation. PLoS One. 2013;8(4):e60895.

67. Guest ST, Kratche ZR, Bollig-Fischer A, Haddad R, Ethier SP. Two members of the TRiC chaperonin complex, CCT2 and TCP1 are essential for survival of breast cancer cells and are linked to driving oncogenes. Exp Cell Res. 2015;332(2):223-35.

68. Zhang Y, Wang Y, Wei Y, Wu J, Zhang P, Shen S, Saiyin H, Wumaier R, Yang $X$, Wang $C$, et al. Molecular chaperone CCT3 supports proper mitotic progression and cell proliferation in hepatocellular carcinoma cells. Cancer Lett. 2016;372(1):101-9.

69. Galmozzi A, Kok BP, Kim AS, Montenegro-Burke JR, Lee JY, Spreafico R, Mosure S, Albert V, Cintron-Colon R, Godio C, et al. PGRMC2 is an intracellular haem chaperone critical for adipocyte function. Nature. 2019;576(7785):138-42.
70. Lee SR, Kwon SW, Kaya P, Lee YH, Lee JG, Kim G, Lee GS, Baek IJ, Hong EJ. Loss of progesterone receptor membrane component 1 promotes hepatic steatosis via the induced de novo lipogenesis. Sci Rep. 2018;8(1):15711.

71. Parker CG, Galmozzi A, Wang Y, Correia BE, Sasaki K, Joslyn CM, Kim AS, Cavallaro CL, Lawrence RM, Johnson SR, et al. Ligand and target discovery by fragment-based screening in human cells. Cell. 2017;168(3):527-41 e529.

72. Hand RA, Craven R. Hpr6.6 protein mediates cell death from oxidative damage in MCF-7 human breast cancer cells. J Cell Biochem. 2003;90(3):534-47.

73. He Y, Zhang P, Zhang D, Xia Z, Wang X, Deng S, Li H, Zhu H, Xu N, Liang S. Combined assessment of low PGRMC1/positive ATP1A1 levels has enhanced prognostic value for renal cell carcinoma. Oncol Rep. 2018;40(3):1467-76.

74. Zhu X, Ji M, Han Y, Guo Y, Zhu W, Gao F, Yang X, Zhang C. PGRMC1dependent autophagy by hyperoside induces apoptosis and sensitizes ovarian cancer cells to cisplatin treatment. Int J Oncol. 2017;50(3):835-46.

75. Zhu X, Han Y, Fang Z, Wu W, Ji M, Teng F, Zhu W, Yang X, Jia X, Zhang C. Progesterone protects ovarian cancer cells from cisplatin-induced inhibitory effects through progesterone receptor membrane component $1 / 2$ as well as AKT signaling. Oncol Rep. 2013;30(5):2488-94.

76. Liu L, Wang J, Zhao L, Nilsen J, McClure K, Wong K, Brinton RD. Progesterone increases rat neural progenitor cell cycle gene expression and proliferation via extracellularly regulated kinase and progesterone receptor membrane components 1 and 2. Endocrinology. 2009;150(7):3186-96.

77. Kim JY, Kim SY, Choi HS, Kim MK, Lee HM, Jang YJ, Ryu CJ. Progesterone receptor membrane component 1 suppresses the p53 and Wnt/beta-catenin pathways to promote human pluripotent stem cell self-renewal. Sci Rep. 2018;8(1):3048.

78. Riester M, Xu Q, Moreira A, Zheng J, Michor F, Downey RJ. The Warburg effect: persistence of stem-cell metabolism in cancers as a failure of differentiation. Ann Oncol. 2018;29(1):264-70.

79. Quin J, Chan KT, Devlin JR, Cameron DP, Diesch J, Cullinane C, Ahern J, Khot A, Hein N, George AJ, et al. Inhibition of RNA polymerase I transcription initiation by CX-5461 activates non-canonical ATM/ATR signaling. Oncotarget. 2016;7(31):49800-18.

80. Gurusinghe S, Young P, Michelsen J, Strappe P. Suppression of dedifferentiation and hypertrophy in canine chondrocytes through lentiviral vector expression of Sox9 and induced pluripotency stem cell factors. Biotechnol Lett. 2015;37(7):1495-504.

81. Gillet LC, Navarro P, Tate S, Rost H, Selevsek N, Reiter L, Bonner R, Aebersold R. Targeted data extraction of the MS/MS spectra generated by dataindependent acquisition: a new concept for consistent and accurate proteome analysis. Mol Cell Proteomics. 2012;11(6):0111.016717.

82. Wang J, Duncan D, Shi Z, Zhang B. WEB-based GEne SeT AnaLysis Toolkit (WebGestalt): update 2013. Nucleic Acids Res. 2013;41(Web Server issue):W77-83.

83. Pawlak M, Schick E, Bopp MA, Schneider MJ, Oroszlan P, Ehrat M. Zeptosens' protein microarrays: a novel high performance microarray platform for low abundance protein analysis. Proteomics. 2002;2(4):383-93.

84. Pirnia F, Pawlak M, Thallinger GG, Gierke B, Templin MF, Kappeler A, Betticher DC, Gloor B, Borner MM. Novel functional profiling approach combining reverse phase protein microarrays and human 3-D ex vivo tissue cultures: expression of apoptosis-related proteins in human colon cancer. Proteomics. 2009;9(13):3535-48.

85. Bader S, Zajac M, Friess T, Ruge E, Rieder N, Gierke B, Heubach Y, Thomas M, Pawlak M. Evaluation of protein profiles from treated Xenograft tumor models identifies an antibody panel for formalin-fixed and paraffinembedded (FFPE) tissue analysis by reverse phase protein arrays (RPPA). Mol Cell Proteomics. 2015;14(10):2775-85.

86. Kaistha BP, Lorenz H, Schmidt H, Sipos B, Pawlak M, Gierke B, Kreider R, LankatButtgereit B, Sauer M, Fiedler L, et al. PLAC8 localizes to the inner plasma membrane of pancreatic Cancer cells and regulates cell growth and disease progression through critical cell-cycle regulatory pathways. Cancer Res. 2016;76(1):96-107.

87. Strauss MP, Liew AT, Turnbull L, Whitchurch CB, Monahan LG, Harry EJ. 3DSIM super resolution microscopy reveals a bead-like arrangement for FtsZ and the division machinery: implications for triggering cytokinesis. PLoS Biol. 2012;10(9):e1001389.

88. Schindelin J, Arganda-Carreras I, Frise E, Kaynig V, Longair M, Pietzsch T, Preibisch S, Rueden C, Saalfeld S, Schmid B, et al. Fiji: an open-source platform for biological-image analysis. Nat Methods. 2012;9(7):676-82.

\section{Publisher's Note}

Springer Nature remains neutral with regard to jurisdictional claims in published maps and institutional affiliations. 


\section{University Library}

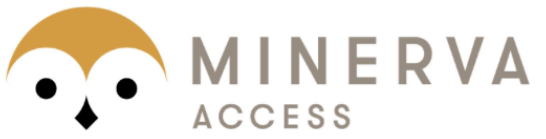

A gateway to Melbourne's research publications

Minerva Access is the Institutional Repository of The University of Melbourne

\section{Author/s:}

Thejer, BM;Adhikary, PP;Kaur, A;Teakel, SL;Van Oosterum, A;Seth, I;Pajic, M;Hannan, KM;Pavy, M;Poh, P;Jazayeri, JA;Zaw, T;Pascovici, D;Ludescher, M;Pawlak, M;Cassano, JC;Turnbull, L;Jazayeri, M;James, AC;Coorey, CP;Roberts, TL;Kinder, SJ;Hannan, RD;Patrick, E;Molloy, MP;New, EJ;Fehm, TN;Neubauer, H;Goldys, EM;Weston, LA;Cahill, MA

Title:

PGRMC1 phosphorylation affects cell shape, motility, glycolysis, mitochondrial form and function, and tumor growth

Date:

2020-04-03

\section{Citation:}

Thejer, B. M., Adhikary, P. P., Kaur, A., Teakel, S. L., Van Oosterum, A., Seth, I., Pajic, M., Hannan, K. M., Pavy, M., Poh, P., Jazayeri, J. A., Zaw, T., Pascovici, D., Ludescher, M., Pawlak, M., Cassano, J. C., Turnbull, L., Jazayeri, M., James, A. C. ,... Cahill, M. A. (2020). PGRMC1 phosphorylation affects cell shape, motility, glycolysis, mitochondrial form and function, and tumor growth. BMC MOLECULAR AND CELL BIOLOGY, 21 (1), https:// doi.org/10.1186/s12860-020-00256-3.

Persistent Link:

http://hdl.handle.net/11343/246072

License:

CC BY 